\title{
Is Fiscal Policy More Effective in Uncertain Times or During Recessions?*
}

\author{
Mario Alloza ${ }^{\dagger}$ \\ BANK OF SPAIN and CENTRE FOR MACROECONOMICS
}

First Version: April 30, 2014

This Version: October 4, 2016

\begin{abstract}
This paper estimates the impact of government spending shocks on economic activity during periods of high and low uncertainty and during periods of boom and recession. We find that government spending shocks have larger impacts on output in booms than in recessions and larger impacts during tranquil times than during uncertain times. The results suggest that confidence plays an important role in explaining this differential impact.
\end{abstract}

Keywords: fiscal policy, vector autoregressions, uncertainty.

JEL classification: E62, E32, C32.

\footnotetext{
${ }^{*}$ I am grateful to Morten Ravn for valuable advice and to Marco Bassetto, Giancarlo Corsetti, Wouter den Haan, Pedro Gomes, Valerie Ramey, Vincent Sterk, Mirko Wiederholt and seminar and conference participants at UCL, University of Cambridge Macroeconomics Workshop, Stockholm School of Economics and ENTER Jamboree 2015 for insightful comments.

†Mario Alloza: Banco de España, Calle Alcalá 48, 28015, Madrid (Spain), m.alloza@bde.es.
} 


\section{Introduction}

How do uncertainty and the state of the business cycle affect the effectiveness of fiscal policy? Economic models incorporating non-convex adjustment costs, as in Bloom et al. (2012), suggest that high levels of uncertainty make agents more cautious when taking investment/hiring decisions, thereby reducing the effect of fiscal policy. "Michaillat (2014) argues that slackness in the economy will improve the effectiveness of some fiscal policies. ${ }^{\square}$ In this paper we attempt to shed light on this question by empirically characterising how uncertainty and the state of the business cycle influence the effects of government spending.

Our empirical strategy is based on a nonlinear structural vector autoregression (SVAR) that allows for differing effects of government spending shocks during times of high (HU) and low (LU) uncertainty, or during times of recession (R) and boom (B). Following Bloom (20)9), we identify periods of HU as those with unusually high stock market volatility. We define periods of $\mathrm{R}$ and $\mathrm{B}$ following the NBER's recording of the dates of business cycles. Exogenous shocks to government spending are identified using two alternative strategies. In the first case, the shocks are identified as the residuals in a SVAR that imposes the exclusion restriction that government spending cannot react within one quarter to shocks to output and tax revenues, as pioneered by Blanchard and Perotti (20102). In the second case, we follow a narrative approach and identify government spending shocks using the news about future defence spending produced by Ramey (2010). The narratively identified shocks are then classified according to whether they occur during times of HU or LU or, alternatively, during times of R or B. This second framework allows us to address issues as anticipation effects of the shocks, and offers an alternative assessment of the exogeneity of the shocks. We apply this methodology to US data between 1948 Q1 and 2007 Q4.

The results suggest that the response of output to a positive government shock is negative during times of $\mathrm{HU}$ or $\mathrm{R}$ and positive during times of $\mathrm{LU}$ or B. Interestingly, the two identification strategies achieve very similar results. These results can be understood in the light of a framework where information is scarce or noisy during times

\footnotetext{
${ }^{1}$ Bloom et aL (2012) develop a model in which uncertainty is time-varying and affects the volatility of technology shocks, and firms are heterogeneous and face non-convex adjustment costs in capital and labour. Fiscal policy is modelled as a wage subsidy. The effect of such a policy is smaller when the policy is implemented at the time uncertainty first hits the economy but slightly larger when the policy is conducted one year later.

${ }^{2}$ Michaillat (2014) considers a New Keynesian model with a search and matching friction where an increase in the size of the public workforce during periods of slack (unemployment increases from 5 to $8 \%$ ) doubles its effect (as measured by the additional number of workers employed when one more worker is employed in the public sector) compared to that under non-recessionary conditions.
} 
of HU. In this context, agents are concerned that the economy may take a downturn and reduce their future levels of income. A government spending shock during times of heightened uncertainty may then simply confirm these pessimistic views, in turn producing a decline in consumption and activity. We find evidence of measures of household-sector confidence reacting negatively to a government spending shock during times of $\mathrm{HU}$, together with consumption and prices.

The results we obtain contrast with previous literature that finds government spending shocks to be more effective in stimulating the economy during periods of $\mathrm{R}$ than $\mathrm{B}$ (Auerbach and Gorodnichenko (2012)). We reconcile the two views and conclude that these differences arise from the information used to define periods of $\mathrm{R}$.

By using the VAR framework to obtain impulse response functions, we are imposing the restriction that responses are fixed for each regime (history-independence). We check whether this is an issue using the local projections of Jordà (2005), as suggested in Auerbach and Gorodnichenko (2013) and Ramey and Zubairy (2014).

Traditional empirical research on fiscal policy, starting with the influential work of Blanchard and Perotti (20)2) and subsequent papers such as Ramey (2011a) and Barro and Redlick (2001), ${ }^{[3}$ has focused on the linear effects of fiscal policy (i.e. the effect of the fiscal policy is assumed to be the same regardless of potentially changing conditions). The conclusion of the above research is that government spending stimulates economic activity, although the precise impact, as measured by the so-called fiscal multiplier, is still controversial (Hall (2010)). Another strand of the literature suggests the opposite effect: government spending cuts have expansionary effects under certain conditions. This is the implication of work by Giavazzi and Pagano (1990) and Alesina and Ardagna $(2013)$.

There is, however, a recent emphasis on allowing for nonlinear effects of fiscal policy, as highlighted in Parker (2010). Corsetti et al. (2013) suggest that the health of public finances might not only affect the magnitude but also the sign of the response of output to government spending. In recessions in an economy with a high level of debt and where monetary policy is constrained (e.g. because of the zero lower bound), an increase in government spending may increase the probability of default, lowering demand. Under certain conditions, the multiplier can shift from positive to zero, or even become negative and large.

\footnotetext{
${ }^{3}$ Other works on the economic effects of government spending include, for example, Ramey and Shapiro (1998), Burnside et al. (2004), Perottil (2004) and Mountford and Uhlig (200.9).

${ }^{4}$ The government spending multiplier is defined as the ratio of output change to an exogenous discretionary increase in government spending. See Ramey (2011b) for a survey on the fiscal multiplier.

${ }^{5}$ See Alesina (2010) for a review of the expansionary effects of fiscal consolidations.

${ }^{6}$ An increasing number of studies are also investigating whether the government spending multiplier
} 
Bertola and Drazen (14993) and Bi et al. (2013) argue that expectations about future government spending can also generate nonlinear effects. These authors explore the idea that cuts in government spending can cause an economic expansion if they induce agents to believe that government spending will be higher in the future. Bi et all (2013) build on this idea and suggest that changes in agents' expectations about fiscal policy (the timing of it and instruments used) can generate positive or negative effects on economic activity, depending on other elements of the economy such as the monetary policy stance or the level of government debt.

A growing body of evidence (Bloom (200.9), Baker et al, (2013)) suggests that uncertainty does have a negative effect on economic activity. However, no research so far provides empirical evidence on how uncertainty affects fiscal policy. ${ }^{\square}$ This question could have important implications from a policy-making standpoint, regarding the extent to which a fiscal intervention may be appropriate during a period of turmoil.

Our work does relate to an increasing amount of empirical studies focusing on whether business cycle conditions are associated with nonlinear effects of fiscal policy, for example Auerbach and Gorodnichenko (2012), Auerbach and Gorodnichenko (2013), Bachmann and Sims (2012), Mittnik and Semmler (2012), Fazzari et all (2012), Bognanni (2012), Owyang et al. (2013), Ramey and Zubairy (2014) and Caggiano et al. (2015). ${ }^{8}$ However, the variety of methodologies employed and the heterogeneity in the definitions of what can be considered a recession (or a slack economy) yield very different results. Some of these studies find that recessions or periods of slack in the economy make government spending a particularly powerful tool. This is true of Amerbach and Gorodnichenko (2012), one of the most prominent studies in this body of literature. These authors use a smooth-transition SVAR in which the probability of recession is weighted by a seven-period centred moving average of the growth rate of output, their measure of the state of the business cycle. Bognanni (2012) finds the opposite: a smaller multiplier during recessions in a Markov-switching VAR in which the probability of recession is estimated period by period. Owyang et al. (2013) and Ramey and Zubairy

can be higher during times when the zero lower bound on nominal interest rates binds. Christiann et al. (2010) argue that large shocks to preferences regarding intertemporal substitution can lead to liquidity traps. In such cases, government spending, by causing inflation, will stimulate output by a much bigger magnitude than during normal times (impact multiplier of 1.6; Fernández-Villaverde et al. (2012) find an impact multiplier of 3 in a nonlinear setting). However, Mertens and Ravn (2014) argue that this effect could be the opposite if we consider that the liquidity trap is caused by an exogenous (sunspot) shock to confidence that drives a shift from optimism to pessimism.

${ }^{7}$ Aastveit et al. (2013) investigate the effects of uncertainty on the effectiveness of monetary policy.

${ }^{8}$ Briickner and Tuladhar (2013) explore the effect of fiscal policy during times of financial crisis. The authors find that firms' financial distress (as measured by a reduction in their net worth because of lower commercial land prices) implies a significantly lower government spending multiplier. 
(2014), meanwhile, find no impact of the state of the business cycle on government spending multipliers.

The present analysis differs from the studies just cited in two important dimensions. First, we use a simple and transparent methodology that allows estimation by OLS and the implementation of different identification strategies for government spending shocks. Second, instead of estimating the probability of recession, or using other variables as ways to estimate the output gap, we employ the definition the NBER uses to measure recession.

The rest of the paper is organised as follows. Section $\square$ describes the empirical strategy and presents the results obtained from the different methods employed to identify the government spending shocks. Since our findings are in striking contrast to previous conclusions in the literature, we investigate the sources of these differences. Section 3 contains different robustness tests for the results of the benchmark specifications. Section $⿴$ concludes and offers directions for future research.

\section{Empirical Strategy}

The empirical literature on the effects of fiscal policy disagrees on which is the best way to identify government spending shocks. The two most commonly used frameworks differ in their assumptions and in the results obtained (see Hall (2010)). ${ }^{\mathbf{9}}$. The Blanchard and Perottil (2002) methodology makes use of an SVAR and identifies exogenous government spending shocks as the only ones that can affect government spending contemporaneously. The second method identifies government spending shocks following Ramey and Shapiro (1.998), who use unexpected changes in defence spending. While recognising that both frameworks have their merits, here we do not take a stance on the suitability of each one but instead use both. They will be described in more detail below.

To define periods of $\mathrm{HU}$ we follow the methodology and data described in Bloom (2009). Bloom (2009) constructs a monthly measure of uncertainty using the VXO index of implied volatility from 1986 onwards and using the actual monthly return volatilities of the SP500 index between 1962 and 1986. ${ }^{\text {⿴囗⿴囗十 }}$ We extend these estimates back to 1948. Major uncertainty events are selected as those months which have a stock market volatility of 1.65 standard deviations above a Hodrick-Prescott trend

\footnotetext{
${ }^{9} \mathrm{An}$ alternative method would be to restrict the sign of some responses of the system to achieve identification, as in Mountford and Uhlig (200.9).

${ }^{10}$ The adequacy of stock market volatility as a measure of uncertainty is also documented in Bloom et al. (2007).
} 
(with a smoothing coefficient of 129,600). Since our sample has a quarterly frequency, we consider periods of $\mathrm{HU}$ to be those quarters containing any of the monthly events described above. $\square$ Periods of LU are defined as the rest of the quarters.

The definition of quarters of $\mathrm{R}$ or $\mathrm{B}$ is done by following the business cycle dates produced by the NBER. Figure $\mathbb{U}$ shows the quarters of HU (32 in total) and those of $\mathrm{R}(35) .{ }^{\square}$

For both specifications the data used contains real federal government spending, output and tax revenues in per capita terms as described in the Appendix. Our sample starts in 1948q1 and finishes in 2007q4.

\subsection{The SVAR Approach}

To capture the potentially different contemporaneous and dynamic responses of the variables to government spending shocks, we estimate an otherwise standard SVAR with dummy variables that provide information about the change in economic conditions (from times of LU to $\mathrm{HU}$ or between $\mathrm{R}$ and $\mathrm{B}$ ):

$$
\begin{aligned}
\boldsymbol{x}_{t} & =\boldsymbol{B}_{L}(L) \boldsymbol{x}_{t-1}+\left(\boldsymbol{B}_{H}(L)-\boldsymbol{B}_{L}(L)\right) H_{t} \boldsymbol{x}_{t-1}+\boldsymbol{e}_{t} \\
\boldsymbol{e}_{t} & =\boldsymbol{D}_{t} \varepsilon_{t} \\
\boldsymbol{D}_{t} & =\left(\boldsymbol{D}_{L}+\boldsymbol{D}_{H} H_{t}\right)
\end{aligned}
$$

where $\boldsymbol{x}_{t}=\left[g_{t}, y_{t}, t r_{t}\right]^{\prime}$ and $\boldsymbol{e}_{t} \sim \mathcal{N}\left(0, \boldsymbol{D}_{t} \boldsymbol{D}_{t}^{\prime}\right)$ is a vector of residuals which are linear combinations of the structural shocks $\varepsilon_{t} \sim \mathcal{N}(0, \boldsymbol{I}) . \boldsymbol{B}(L)=\left(\boldsymbol{I}-\boldsymbol{B}_{1} L-\boldsymbol{B}_{2} L^{2} \ldots \boldsymbol{B}_{p} L^{p}\right)$ represents a lag polynomial of order $p$. 푸

$H_{t}$ is a dummy variable that takes a value of one during periods of $\mathrm{HU}$ (or R, depending on the analysis). ${ }^{\mathbb{4}}$ When $H_{t}=0$, the dynamic lagged variables affect the system through $\boldsymbol{B}_{L}(L)$, and when $H_{t}=1$ through $\boldsymbol{B}_{H}(L)$, allowing for a potentially different dynamic response in the system. The contemporaneous response matrix $\boldsymbol{D}_{t}$ is also allowed to be state-dependent, changing during periods of LU or B (matrix $\boldsymbol{D}_{L}$ ) and periods of HU or R (matrix $\boldsymbol{D}_{H}$ ). The specification also includes a state-varying constant and a quadratic trend (as emphasised in Francis and Ramey (200). )).

\footnotetext{
${ }^{11}$ The results are very similar when we consider quarterly volatility (instead of monthly) and pick up the periods with unusually high values.

${ }^{12}$ See Bloom (20)9) for a complete characterisation and description of the HU events since 1962.

${ }^{13}$ We set $p=4$ following Blanchard and Perottil (20102) and Ramey (201]a).

${ }^{14}$ Some studies (see Auerbach and Gorodnichenko (2012)) advocate using $H_{t-1}$ instead of $H_{t}$ to avoid contemporaneous feedback from fiscal policies into the state of the economy. Our results are similar regardless of which specification we use.
} 
In the framework of this subsection, exogenous shocks to government spending are identified using an exclusion restriction: government spending does not react contemporaneously to other structural shocks. This assumption implies that there is a time lag of one quarter required to enact public spending bills. Following Blanchard and Perottil (20102), the plausibility of this restriction rests on the minimum required time that the fiscal authority faces when adjusting government spending to surprise changes in fiscal (as measured by shocks to tax revenues ) or general (as measured by shocks to output) macroeconomic conditions. To implement this restriction, the matrix $\boldsymbol{D}_{t}$ is obtained from a Choleski decomposition of the variance-covariance matrix of the relevant residuals from equation $\mathbb{\square}$, where government spending is ordered first.

To prevent the nonlinearities that are present in equation $\square$ from altering the original Blanchard-Perotti identification assumption, we impose 0 coefficients on the matrix $\boldsymbol{B}_{1}(L)=\boldsymbol{B}_{H}(L)-\boldsymbol{B}_{L}(L)$ for the government equation. Therefore, government spending shocks $\varepsilon_{t}^{g}$ are identified, in line with Blanchard and Perottil (2002), from:

$$
g_{t}=\sum_{j=1}^{p} \boldsymbol{\beta}_{0, j}^{g} \boldsymbol{x}_{t-j}+\varepsilon_{t}^{g}
$$

When we do not allow for differential responses due to changing economic distinctions, i.e. $H_{t}=0$ for all periods, equation $\square$ reduces to a standard linear SVAR model:

$$
\boldsymbol{x}_{t}=\boldsymbol{B}(L) \boldsymbol{x}_{t-1}+\boldsymbol{D} \boldsymbol{\varepsilon}_{t}
$$

We start by estimating equation $\mathbb{t}$ to establish a comparison with previous work. Figure [ shows the responses of the variables in the system to a positive shock in government spending that raises government spending by $1 \%$ at its peak. The figure also shows $68 \%$ and $95 \%$ confidence intervals, computed using a non-parametric bootstrap method. ${ }^{\text {W }}$ The response of output is positive throughout the horizon (20 quarters). The implied elasticity of the GDP on impact with respect to the government spending peak is 0.045 . When translated into multiplier terms, the impact multiplier is 0.46 , increasing to 0.85 at the peak. ${ }^{[6]}$ The results are qualitatively similar (although slightly smaller in size) to Blanchard and Perottil (20122), with output reaching its peak impact after the fourth year).

We now relax the implied assumption that changes in government spending always

\footnotetext{
${ }^{15}$ To compute the confidence intervals, we generate 100,000 bootstrap draws of the endogenous variables using the estimated coefficients $\left(\hat{B}_{H}(L)\right.$ and $\left.\hat{B}_{L}(L)\right)$ and residuals $\left(\hat{e}_{t}\right)$ from equation $\square$. We re-estimate the VAR using the bootstrap samples and compute the 68 th and 95th percentiles of the resulting impulse responses.

${ }^{16}$ The ratio of nominal GDP to nominal federal government spending in our sample is 10.13 .
} 
have the same effect. When allowing for nonlinearities as described in equation $\mathbb{W}$, the results change dramatically. We start with the case where $H_{t}$ takes a value of 1 during periods of $\mathrm{HU}$ as described above. Figure 3 shows the responses to a positive shock to government spending. The first panel (in blue) shows the responses of the variables in the system during times of LU. The response of output is slightly higher than in Figure 2 (0.56 on impact, implying an impact multiplier of almost 0.6 , and about 1 at the peak) and remains significant throughout the 20 quarters considered. The responses of government spending and tax revenues are qualitatively similar to the linear case. The bottom panel (in red) of Figure 3 shows the response to the same shock during times of HU. In striking contrast with the previous case, a positive government spending shock is associated with a large, significant and negative response of output. The effect of the shock is small on impact but it builds up progressively until after the second year, with an elasticity of -0.48 (which in our sample would imply a peak multiplier of -4.9). The response of government spending during times of $\mathrm{HU}$ has a similar shape to the linear case during the first three years, although it exhibits more persistent effects from the shock.

Next, we consider the case of nonlinearities caused by the state of the business cycle ( $H_{t}$ takes a value of 1 during periods of $\mathrm{R}$ ). The responses are shown in Figure 6 . During times of $\mathrm{B}$, the response of output is positive and very similar to the linear case during the first three quarters, although the shock now has very temporal effects and output becomes slightly negative but insignificant during the rest of the horizon. ${ }^{\text {Wa }}$ During times of $\mathrm{R}$, the response of output to a positive increase in government spending is instead estimated to be negative. The magnitude of this effect is, however, smaller than in the case of the HU periods considered earlier (the elasticity at the peak is -0.1).

These results suggest that the response of output to government spending shocks does not remain the same across all states of the economy. In particular, it becomes negative when we consider periods of $\mathrm{HU}$ or $\mathrm{R}$.

\subsection{The Narrative Approach}

In this subsection, we use a different framework to achieve identification of the government spending shocks while retaining the potentially different effects of these on the variables in the system.

The specification described in equation $\square$ relies on two assumptions: (i) government spending shocks are a surprise to agents and (ii) government spending cannot react

\footnotetext{
${ }^{17}$ Note that this is not the case when we consider a stochastic trend, as in the appendix.
} 
within one quarter to other shocks affecting the economy. However, it could be the case that government spending plans are anticipated by agents, which would violate assumption (i) above. This possible mistiming of events has been voiced as a criticism of SVAR approaches such as that expressed by equation (Ramey (201Ta)). To avoid this potential issue, we use the measure of news about future government spending (as a percentage of GDP) described in Ramey (20la) to identify exogenous shocks. ${ }^{\text {एव }}$

Regarding the second assumption, it could be argued that the intervention lag of one quarter taken by the fiscal authorities to respond to developments in the economy, assumed in the previous subsection, is more likely to be violated during times of $\mathrm{R}$ or HU (since it could be the case that governments will act faster in passing bills in such times). This would cause a problem of a lack of exogeneity. The use of narrative identification of shocks using news about defence spending again allows us to deal with this problem, since the defence news variable is more likely to be driven by exogenous foreign political events, wars, etc (Ramey (201/a)).

We now estimate a VAR that explicitly incorporates the structural shocks to government spending, namely $\varepsilon_{t}^{\text {Ramey }}$, or news about defence spending:

$$
\boldsymbol{x}_{t}=\boldsymbol{B}(L) \boldsymbol{x}_{t-1}+\boldsymbol{C}(L) H_{t} \varepsilon_{t}^{\text {Ramey }}+\boldsymbol{D}(L)\left(1-H_{t}\right) \varepsilon_{t}^{\text {Ramey }}+\boldsymbol{\xi}_{t}
$$

As before, $\boldsymbol{B}(L)$ is a lag polynomial of order $p$ and $\boldsymbol{C}(L)$ and $\boldsymbol{D}(L)$ are lag polynomials of order $q .{ }^{\mathbb{1 0}} \boldsymbol{\xi}_{t}$ is a residual with normal distribution. As in equation $\boldsymbol{\square}$, the above model allows for government spending shocks to have differential effects, both dynamically and on impact, depending on the evolution of features of the economy

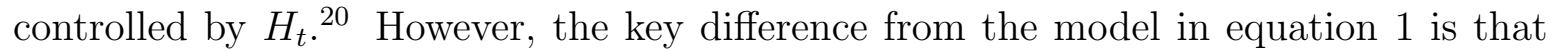
the structural shocks $\varepsilon_{t}^{\text {Ramey }}$ are now assumed to be observable variables. ${ }^{\text {WD }}$

When we exclude differential effects of government spending shocks due to economic conditions (i.e. $H_{t}=0$ for all periods), equation 5 reduces to the standard linear case considered in Ramey (201a):

\footnotetext{
${ }^{18}$ Ramey (201/a) constructs a time series of the expected discounted values of government spending changes by obtaining quantitative information about estimated defence spending from periodicals (hence its name of narrative identification). A simpler approach based on the same strategy can be found in Ramey and Shapiro ([1998), where the authors use war dates to identify exogenous changes in defence spending.

${ }^{19}$ Following similar studies such as Romer and Romer (2010), we set $q=12$.

${ }^{20}$ When $H_{t}$ takes a value of 1 , the contemporaneous and dynamic effects of the shock $\varepsilon_{t}^{\text {Ramey }}$ are given by the matrix $\boldsymbol{C}(L)$. Conversely, when $H_{t}=0$ these effects are controlled by the matrix $\boldsymbol{D}(L)$.

${ }^{21}$ Section 3 relaxes the assumption that the structural shocks $\varepsilon_{t}^{\text {Ramey }}$ are perfectly observable and considers the case of shocks measured with error.
} 


$$
\boldsymbol{x}_{t}=\boldsymbol{B}(L) \boldsymbol{x}_{t-1}+\boldsymbol{F}(L) \varepsilon_{t}^{\text {Ramey }}+\boldsymbol{\xi}_{t}
$$

To compare our results to others in the literature, we start by estimating equation [6. Figure 5 shows the responses of the variables in the system to a positive shock in government spending that raises government spending by $1 \%$ at its peak. As before, the figure also shows the $68 \%$ and $95 \%$ confidence intervals, computed using a nonparametric bootstrap method. The response of output peaks after the second year with an elasticity of 0.47 (multiplier of 0.52 ), although it is mostly insignificantly different from 0 throughout the horizon (20 quarters). Ramey (2017a) finds a positive and significant response of output when including data from WWII (and other controls, such as the interest rate), although she also finds a similar response to the one found here when excluding both WWII and the Korean War. She concludes that the variable of defence shocks is not informative enough for the post-Korean-War sample.

The results change dramatically when we allow for nonlinear effects as considered in equation [. Figure 6 show the responses to a positive shock to government spending for the case where $H_{t}$ takes a value of 1 during periods of $\mathrm{HU}$ as described above. Interestingly, responses of output during both states (LU in the top panel in blue, and $\mathrm{HU}$ in the bottom panel in red) are now mostly significant. The signs of the responses follow the same pattern as in the previous subsection, with output reacting positively to a government spending shock during LU, and negatively during $\mathrm{HU}$. In periods of LU, following a positive shock to government spending, output grows by 0.049 and peaks together with government spending before the second year, with an implied elasticity of 0.18 (equivalent to a multiplier of 0.54 on impact and one of about 2 at the peak). Despite the difference between the two identification approaches, the responses during $\mathrm{HU}$ are very similar to those obtained using the Blanchard-Perotti restrictions. Output falls by almost -0.04 on impact and reaches -0.4 at the end of the first year (which implies an impact multiplier of -0.4 , and -4.35 at the peak).

Surprisingly, while the linear estimation (Figure 1 ) showed little response of output to a government spending shock, the nonlinear estimation uncovers a very different scenario: output reacts positively (and strongly) during times of LU and negatively during times of $\mathrm{HU}$ (in a magnitude very similar to that found in the previous identification approach).

Figure $\square$ shows the responses when $H_{t}$ takes a value of 1 during periods of R. Again, the response of output is significantly different from 0 at most forecast horizons (as opposed to in the linear case). Output reacts positively to a government spending shock during times of B: it peaks at 0.13 together with government spending at the end 
of the third year, implying a multiplier of 1.4. The response of output is negative when the shock happens during a time of $\mathrm{R}$, although in this case the response is noticeably larger in magnitude (elasticity of -0.7). The responses of government spending, as in the case of $\mathrm{HU}$ and LU, are persistent.

The narrative identification approach corroborates the results obtained in the previous subsection: the response of output to a government spending shock depends on the evolution of features of the economy such as the level of uncertainty or the state of the business cycle. The nonlinear estimation also offers a different view to that of the linear case when using the Ramey (201/a) narrative variable, showing that government spending is in fact a powerful instrument in stimulating output (during times of $\mathrm{B}$ or LU).

\subsection{Understanding the Results}

Why do high levels of uncertainty or a recessionary economy affect the impact of exogenous changes in government spending? The above analysis suggests that there is a mechanism that operates differently when the economy is in a state of HU (or R). In this subsection, we consider the role of a change in confidence as the device inducing the differing responses in the empirical analysis. ${ }^{22}$

We interpret a shift from times of LU to $\mathrm{HU}$ as a deterioration in the information set available to agents. ${ }^{\text {[. }}$ In a context of scarce information, households may become more cautious, rendering their confidence sensitive to signals that may confirm their pessimism about their future income levels.

In such a situation, an increase in government spending could serve to corroborate the idea that the productivity of the economy was low, triggering a shift to pessimism among households. The likely result of the deterioration in households' confidence would be that consumption would decrease in view of potentially low levels of income. Firms would respond to this decrease in demand by lowering production and prices, which would have a contractionary effect on the overall economy.

\footnotetext{
${ }^{22}$ We focus on a mechanism that acts differently during times of HU and times of LU (rather than during times of $\mathrm{B}$ and times of $\mathrm{R}$ ). Although uncertainty could be endogenously generated during $\mathrm{R}$ (see Bloom (2014) for a discussion), the definition of periods of HU here is mostly based on exogenous events (Bloom (2009)), which makes uncertainty a better candidate with which to explain the above results. Since periods of HU and R do not always overlap, we could test which is the ultimate driving force behind the differing responses observed above (heightened uncertainty or a slack economy). Unfortunately, the data are too scarce for us to draw conclusive results on this.

${ }^{23}$ This can be due to scarce information or a reduction in its accuracy. As defined by Frank Knight (1921), uncertainty is found in situations where agents cannot attach probability distributions to some events. This represents the inability of agents to form accurate predictions about, for example, the level of productivity in the economy or the income levels expected by households.
} 
To support this conjecture, we analyse the responses of some relevant variables to a government spending shock. ${ }^{[4}$ Figure $\mathbb{8}$ shows the responses of three measures of confidence to a government spending shock during times of LU and HU. The first two columns correspond to the Consumer Confidence Index (CCI) and the Index of Consumer Sentiment (ICS), two popular measures of households' confidence. ${ }^{\text {.5. Both }}$ variables react positively to a government spending shock when it takes place during a time of LU, but decrease when shocks occur during times of HU (the CCI decreases markedly and significantly while the ICS does so in a less significant manner). The third column of Figure $\mathbb{8}$ plots the response of an indicator of industrial confidence in the manufacturing sector (the Business Conditions Indicator from the OECD), which behaves similarly. This evidence suggests that government spending shocks lower the confidence of agents if they occur during times of heightened uncertainty, while they boost their confidence during normal times.

This shift towards pessimism translates into a higher demand for precautionary savings by households. Figure $\mathbb{Q}$ shows a significant reduction in consumption in response to government spending shocks during times of HU. In such a scenario, firms would optimally respond to declining demand by lowering prices. This is consistent with the second column of Figure $\mathbb{9}$, which shows that actual (dashed line) and expected (solid line) inflation do not react significantly to the shock during LU, but they decline when the shock occurs during a time of HU. ${ }^{\mathbb{6}}$ The last column of Figure $\mathbf{Q}$ shows the response of interest rates to a government spending shock. As could be expected from the response of the monetary authority to developments in inflation, the interest rate declines after a shock during a time of HU (and remains roughly constant after a shock that occurs in a time of LU).

\footnotetext{
${ }^{24}$ We use narrative identification based on Ramey's news about defence spending. Following Burnside et al. (2004) and Ramey (201/a), we use the fixed set of variables $\boldsymbol{x}_{t}$ described above and rotate the new variables of interest into the analysis.

${ }^{25}$ The CCI measures consumer confidence by using the monthly responses of 5,000 US households to questions on their current and expected (within the next six months) business, family income and employment conditions. The CCI is computed as the proportion of participants that respond positively to these questions. Data for this variable is available from 1967 Q1 onwards. Similarly, the ICS is computed by combining the proportions of interviewed people who express favourable opinions on their current and expected (within the next twelve months) financial situation and the business conditions in the country, on their expectations for the next five years about the economic situation, and about their purchases of durable goods in the current period. The ICS uses responses from 500 telephone interviews and is available from 1960 Q1 onwards.

${ }^{26}$ Expected inflation is measured by the median inflation forecast over the next 12 months from the Survey of Consumers (University of Michigan). The results are qualitatively similar when we use inflation forecasts from the Survey of Professional Forecasters.
} 


\subsection{Relation to Other Studies}

Our empirical results suggest that government spending shocks have negative effects on output during recessions. Other studies arrive at the opposite conclusion: recessions make government spending more expansionary than booms. In order to understand why these findings are so different, we now compare our results with those of Auerbach and Gorodnichenko (2012), whose study is one of the most prominent in this area. ${ }^{[2]}$

Auerbach and Gorodnichenko (2012) use a Smooth-Transition VAR to investigate the variation in the response of output between periods of $\mathrm{R}$ and $\mathrm{B}$. They estimate the following model:

$$
\begin{aligned}
\boldsymbol{x}_{t} & =\left(1-H_{t-1}^{A G}\right) \boldsymbol{C}_{B}(L) \boldsymbol{x}_{t-1}+H_{t-1}^{A G} \boldsymbol{C}_{R} \boldsymbol{x}_{t-1}+\boldsymbol{e}_{t} \\
H_{t}^{A G} & =\frac{\exp \left(-\gamma z_{t}\right)}{1+\exp \left(-\gamma z_{t}\right)} \\
\boldsymbol{e}_{t} & \sim \mathcal{N}\left(0, \boldsymbol{\Omega}_{B}\left(1-H_{t-1}^{A G}\right)+\boldsymbol{\Omega}_{R}\left(H_{t-1}^{A G}\right)\right) \\
\operatorname{var}\left(z_{t}\right) & =1, E\left(z_{t}\right)=0
\end{aligned}
$$

where $\boldsymbol{x}_{t}$ is the same vector of variables as defined above. The model allows for a differential impact of the government spending shock both contemporaneously (through matrices $\Omega_{B}$ and $\Omega_{R}$ ) and dynamically (through matrices $\boldsymbol{C}_{B}(L)$ and $\boldsymbol{C}_{R}(L)$ ) during booms and recessions. The transition between these two states is governed by a logistic function $H_{t}^{A G}$ that depends on the variable $z_{t}$, which is defined as the centred moving average (MA) of order 7 of the growth rate of real GDP.

Despite an apparently similar framework, the results generated by the two different estimation approaches (the model described by equation $\square$ and those described by equations $\mathbf{U}$ and 5) are very different: Auerbach and Gorodnichenko (2012) find that a government spending shock that occurs during a time of $\mathrm{R}$ has a positive and larger effect than the same shock occurring during a time of B.

Why do similar estimation methods yield such contrasting results? The answer to this question rests on the information used to determine the current state of the economy. Equation $\square$ uses a continuous variable determined by a centred MA of the growth rate of real GDP, while equation $\square$ includes a binary variable that follows the

\footnotetext{
${ }^{27}$ Ramey and Zubairy (2014) propose a different estimation method using local projections (see Section [1) and historical data from 1889 to 2011. They find no significant differences in responses during periods of B and R. However, when their methodology and data are used for the post-War period used in this paper, the results are very similar to those presented in Section $\nabla$ (with output contracting after positive government spending shocks during times of $\mathrm{R}$ ).
} 
NBER definition of recession. ${ }^{[8}$ Constructing $H_{t-1}^{A G}$ in equation $\square$ in such a way has potentially important implications. By using a centred MA of order $j$ (a two-sided MA filter), at any given period of time, we are making use of future developments in GDP to inform about the current state of the economy. For example, in period $t$, whether the economy is in recession or expansion will be determined by information up to period $t+(j-1) / 2$. In the event of an incoming change in the business cycle (e.g. from an expansion to a recession), we could potentially be mislabelling the current state of the economy.

In order to determine whether the nature of the two-sided MA filter can explain the differences between the two sets of results, we replicate the benchmark analysis in Amerbach and Gorodnichenko (2012) for different sizes of the centred MA of the growth rate of real GDP. Figure 10 shows the responses of GDP and government spending to a positive shock to the latter during times of $B$ and $R$ when varying the size of the MA from 5 up to 19. The results suggest that the impact of the shock on GDP does depend on the size of the MA filter: using a high-order MA (i.e. using more information that has not yet occurred) reduces the effect of the shock during times of B (with the effect even becoming negative in the medium run) and augments it during times of $\mathrm{R}$. When the size of the benchmark specification in Auerbach and Gorodnichenko (2012) (a MA of order 7 ) is reduced to a MA of order 5 , the results become qualitatively the same as those described earlier in this paper: a government spending shock has a positive effect on GDP during times of $\mathrm{B}$ and a negative effect during times of $\mathrm{R}$.

Next, we analyse how the results in Auerbach and Gorodnichenko (2012) would be affected if the centred MA were substituted by a one-sided MA filter (i.e. keeping the length of the MA filter constant, but altering its symmetry). Figure $\mathbb{W}$ shows the responses to a government spending shock when we use (i) the benchmark specification (centred MA of order 7), (ii) a one-sided MA filter of order 7 that only uses past information and (iii) a one-sided MA filter that exclusively uses future information. The results confirm that, when not using information about the future (i.e. when the MA is only backward-looking), the response of output becomes more similar to those obtained from equations $\mathbf{U}$ and 5 : a government spending shock has positive effects during a period of $\mathrm{B}$, but negative ones during a period of $\mathrm{R}$ (while the opposite is true when a forward-looking MA filter is used).

We conclude that the differences between the results presented in this paper and those in Auerbach and Gorodnichenko (2012) respond to the information used to explain

\footnotetext{
${ }^{28}$ When we redefine $H_{t-1}^{A G}$ in equation $\square$ to be a dummy variable, the results are qualitatively similar.

${ }^{29}$ Cases in between these two extremes (e.g a MA(7) filter that uses information from the last two quarters and the next four quarters) support the same conclusions.
} 
changes in the state of the economy.

\section{Robustness}

\subsection{Alternative Timing of Uncertainty Events}

In this subsection we analyse the sensitivity of the results to changes in the definition of the episodes of HU. In Section 2, these were defined as quarters containing any month with unusually high stock market volatility (1.65 standard deviations above a HodrickPrescott trend). The advantage of this approach is that it produces a larger number of periods of HU (32 quarters). We now strictly apply the definition of episodes of HU in Bloom (2009) and consider only those quarters that contain months of peak volatility. ${ }^{3}$

To assess whether this change of definition affects our results, we estimate equations $\mathbf{W}$ and $\mathbf{5}$ again using the alternative definition of HU. Figure $\square 2$ displays the results of a government spending shock identified using the SVAR approach (equation $\square$ ). The response of the variables during times of LU is almost unchanged between the alternative (solid line) and benchmark (dashed line) definition of episodes of uncertainty. During times of HU, the response of output is fairly similar for both definitions during the first two years after the shock. The most noticeable difference is that the alternative definition produces more persistent effects of the shock.

Next, we consider the case of the narrative identification of government spending shocks (equation 5). Figure [13 plots the results for this case. The responses of the variables during LU is are almost identical for both definitions of uncertainty. When considering times of $\mathrm{HU}$, the response of output is again very similar in each case during the first two years. The magnitude of the decline in output is larger for the alternative definition (dashed line) between the second and fifth years of the horizon.

We can conclude that the finding of different signs of the responses of output during times of $\mathrm{HU}$ and LU is robust when we consider uncertainty episodes as defined by quarters of peak stock market volatility.

\footnotetext{
${ }^{30}$ Bognanni (2012) uses a Markov-switching VAR where the probability of recession is estimated period by period, and finds that the effect of a government spending shock on activity is smaller during periods of $\mathrm{R}$ than $\mathrm{B}$.

${ }^{31}$ For example, from 2002 Q3 to 2003 Q1 stock market volatility was 1.65 standard deviations above the trend, due to the second Gulf War. In our benchmark definition of episodes of HU this resulted in three quarters of HU. In the alternative definition proposed now, we only consider the quarter with the highest volatility (in this case, 2003 Q1).
} 


\subsection{Local Projections}

Equations $\mathbb{W}$ and 5 both imply restrictions on the responses of the variables to structural shocks. Responses are linear when conditioning on a given state and are therefore history-independent. This is equivalent to assuming that fiscal policy, through government spending, cannot change the regime from $\mathrm{HU}$ to $\mathrm{LU}$ (or from $\mathrm{R}$ to $\mathrm{B}$ ) or vice versa. While uncertainty is defined here as exogenous events (most of the episodes of $\mathrm{HU}$ are not economics-related), these events are mostly short-lived. It is also plausible to believe that government spending can influence the economic situation. Although these shortcomings are less likely to appear in the short run, we follow Auerbach and Gorodnichenko (2013) and Ramey and Zubairy (2014) in using a methodology that takes these issues into account. We use the local projection methodology proposed in Jordà (201(15), which relaxes the assumption that the state of the nonlinear model remains fixed throughout the entire horizon of the impulse response analysis.

The local projection methodology estimates a series of single equations over the horizon $h$ :

$$
\begin{aligned}
& x_{t+h}=H_{t-1}\left[\alpha_{L, h}+\beta_{L, h} \boldsymbol{x}_{t-1}+\delta_{L, h} \varepsilon_{t}^{G}\right]+ \\
& \left(1-H_{t-1}\right)\left[\alpha_{H, h}+\beta_{H, h} \boldsymbol{x}_{t-1}+\delta_{H, h} \varepsilon_{t}^{G}\right]+e_{t+h}
\end{aligned}
$$

where $\boldsymbol{x}_{t}=\left[g_{t}, y_{t}, t r_{t}\right]^{\prime}$ is the vector of variables defined in the previous section and $x_{t}$ is one of the variables of interest in $\boldsymbol{x}_{t}$. Note that equation $\mathbb{W}$ allows for the coefficients to change for each horizon $h$. The coefficient $\delta_{L, h}$ measures the response of the variable $x_{t}$ to a government spending shock $\varepsilon_{t}^{G}$ during state $L$ (which represents times of LU or B) and, conversely, $\delta_{H, h}$ captures the response during state $H$ (times of HU or R). The responses of the variable of interest to government spending shocks during state $L$ (or $H)$ are given by a series of $\delta_{L, h}\left(\right.$ or $\delta_{H, h}$ ) obtained from each regression $h$.

We apply the above method using both of our identification schemes mentioned earlier. Thus, $\varepsilon_{t}^{G}$ represents either the government spending variable (to achieve the Blanchard-Perotti SVAR identification) or Ramey's news about defence spending (narrative identification).

Figure [14 shows the responses to a government spending shock identified as in Blanchard and Perottil (20102) when equation $\square$ is allowed to vary between states of HU or LU. The response of output is positive and significant during times of LU. During times of HU, the point estimate (solid line) is not significant during the first two years and then becomes negative. This figure also displays the point estimate when the episodes of $\mathrm{HU}$ are identified using the alternative measure of uncertainty explained in the previous subsection (dashed line). This estimate is negative and significant 
(confidence intervals for this estimation are not shown) throughout the entire impulse response horizon.

We now replicate the same analysis but using the narrative identification approach for the government spending shock. Figure 15 displays the responses. As in the previous case, the response of output is positive and mostly significant during times of LU. The sign of this response becomes negative and significant when the shock happens during a time of HU. The same result obtains when we consider the alternative definition of HU (dashed line) although the magnitude of the decline in output is significantly larger. ${ }^{22}$

Finally, we consider the business cycle conditions ( $\mathrm{R}$ or $\mathrm{B}$ ) to be the drivers of the nonlinearities in equation $\mathbb{}$. Figure [6] plots the responses to government spending shocks identified using the SVAR framework. In times of B, the response of output is positive and mostly significant. During times of $R$, the response is negative during the first year but only significant up to $68 \%$, and then fluctuates for the rest of the horizon considered (increasing after the fourth year).

Figure $[7$ displays the responses when the government spending shock is identified following the narrative approach. The response of output is positive but small during times of B. During times of R, output declines during the first year and remains negative or close to zero up to the fourth year (after which it increases), although the levels of significance are low.

To summarise, the local projection framework shows that the nonlinear responses due to different levels of uncertainty are not caused by the restriction imposed by the VAR (i.e. the state remaining fixed for the whole impulse response horizon). The results are, however, less clear when we consider nonlinearities due to the state of the business cycle.

\subsection{Alternative Identification Strategy}

In this subsection we use a different strategy to identify the government spending shocks. In Section $\square$ we used the Ramey (201/a) narrative shock of news about defence spending as the true structural shock to government spending. One might suppose that this series could be contaminated by measurement errors. We now follow Mertens and Ravn (2013) and consider the possibility that the narrative shocks are not the true structural shocks but a measure correlated with them. We assume as well that this measure, the proxy, is orthogonal to other structural shocks. These assumptions give us extra identification restrictions (exploiting the correlation between the proxy and the reduced form residuals

\footnotetext{
${ }^{32}$ Note that these responses, unlike those shown in Section $\mathbf{2}$, are not scaled to the government spending shock, since we are estimating single equations.
} 
of the SVAR) that can be used in conjunction with the covariance restrictions from the VAR in equation $\square$ to identify the structural shocks to government spending. ${ }^{\text {[3. }}$

Figure 18 plots the responses when using this alternative identification, for the case of HU versus LU. The response of output follows a similar pattern to that in the benchmark results: it increases as a result of a government spending shock during a time of LU but becomes negative when the shock takes place during a time of HU, with a magnitude very similar to the results presented in Section 2 .

Next we consider the case of responses to government spending shocks during times

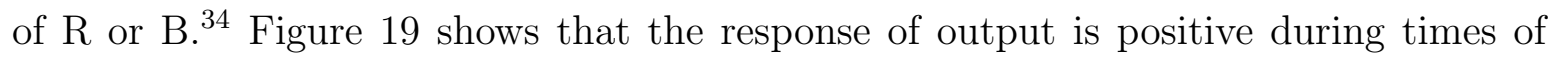
B. Output declines during times of $\mathrm{R}$, with an implied elasticity of the output peak to the government spending peak of $-0.3 \%$ after the first year. The magnitude of this response falls between the results obtained in Section 2 for the SVAR and narrative identification approaches.

\subsection{Alternative Narrative Measure}

In Section $\square$ we used the Ramey (201/a) news about defence spending as the government spending shocks. Ramey (2017a) produces a second narrative measure: news shocks based on the one-quarter-ahead forecast error of defence spending by professional forecasters. ${ }^{[3}$ Ramey (201a) reports that shocks to this variable are associated with decreasing output. We find similar results when we estimate the linear version of equation 5 with these shocks (as shown in Figure [20)

We want to investigate whether the response of output is still qualitatively different across states when we consider this alternative identification of government spending shocks. We estimate equation 9 , allowing for nonlinearities due to periods of HU or LU but using the new narrative measure. Figure $2 \mathbb{1}$ shows the responses after a government spending shock in this case. During times of LU the response of output is positive on impact, before becoming negative and then insignificant (the point estimation becomes positive again after the third year, in contrast with the linear case displayed in Figure 20

\footnotetext{
${ }^{33}$ Note that we no longer need the Blanchard and Perottil (2002) exclusion restrictions on the contemporaneous impact of a government spending shock in order to achieve identification.

${ }^{34} \mathrm{We}$ find that the results during times of $\mathrm{B}$ are very imprecisely estimated when we include the recession of 1949. In this particular case we consider 1950 Q1 as the starting date of our sample. The results for the case of Rare not dependent on this consideration.

${ }^{35}$ Ramey (201a) suggests that the explanatory power of the defence news variables may be lower when the sample starts after WWII and the Korean War (we include only the latter), the two major events of increases in government spending.

${ }^{36}$ Ramey says: "these shocks lead to rather contractionary effects, similar to those I found for the 1955 to 2008 period with my defence news shocks", a statement that we have illustrated in Figure 5.

${ }^{37}$ The sample starts in 1969 Q1, restricted by the availability of the data.
} 
in which it remained negative during the entire period). When considering the response of output during times of $\mathrm{HU}$, we again observe a large and significant decline following the shock, as in the results presented in Section 2 .

We now consider the case of the impact of a government spending shock during times of R and B. Figure 22 shows the responses for this case. We again observe an initially positive response of output during times of $\mathrm{B}$, becoming negative (and then insignificant) after the third quarter. The response of output during times of $\mathrm{R}$ is negative and significant, as observed in the benchmark results.

\section{Conclusion}

The effect of government spending is likely to depend on features of the economy that evolve over time. In this paper, we study whether the effects of changes in government spending remain the same across states of the economy. In particular, we empirically characterise how changes in government spending may differ across states of high (HU) and low (LU) uncertainty and across recessions (R) and booms (B).

Our results suggest that the impact of government spending shocks on output is positive during times of $\mathrm{LU}$ or $\mathrm{B}$ and negative during times of $\mathrm{HU}$ or R. We find that households' confidence is a key variable for interpreting these results, as agents become more pessimistic when a positive government spending shock confirms their views on the state of the economy.

Other studies in the literature (such as Amerhach and Gorodnichenko (2012)) produce contrasting results. We explore these differences by highlighting the importance of the information used to determine the state of the business cycle.

The results documented here provoke new research questions. For example, we have seen that output contracts after a positive government spending shock if that shock happens during a time of HU or R. It would be interesting to identify whether it is $\mathrm{HU}, \mathrm{R}$ or a combination of both that is causing this effect. This would require a comparison between a shock that happens in a time of $\mathrm{HU}$ and $\mathrm{B}$ and a shock that happens during a time of LU and R. However, the data are not informative enough for this, since there are just a few events with these characteristics, insufficient for us to obtain robust results. More empirical evidence is required to help us shed light on this question.

It is also necessary to understand the mechanism causing these differing impacts of government spending on the economy. Here we have highlighted the importance of households' confidence in explaining the results. A detailed theoretical framework that 
can explain such nonlinear effects would be crucial for evaluating the consequences of public policies.

We have focused our attention on uncertainty that has an arguably exogenous origin (e.g. war, terror). However, uncertainty can be generated by endogenous causes, for example by policy itself (see Baker et al. (2013), Fernández-Villaverde et al. (2011) or Bi et al. (2013)). ${ }^{\text {B }}$ Whether and how this source of fiscal uncertainty can affect real activity are questions left for future research.

\footnotetext{
${ }^{38}$ Uncertainty derived from fiscal policy has received attention from the media recently. See, for example, The Economist (16/11/2013): "Governments, however, are still breeding fears about the future. The most glaring form of uncertainty in the rich world is fiscal. [...] This is self-imposed uncertainty. If the fiscal path were a little clearer, the reduction in uncertainty should spur investment and output, which in turn should improve the fiscal picture."
} 


\section{References}

Aastveit, K. A., Natvik, G. J., and Sola, S. (2013). Economic Uncertainty and the Effectiveness of Monetary Policy. Unpublished manuscript, Norges Bank.

Alesina, A. (2010). Fiscal Adjustments: Lessons from Recent History. In ECOFIN meeting, Madrid, April, volume 15.

Alesina, A. and Ardagna, S. (2013). The Design of Fiscal Adjustments. In Tax Policy and the Economy, Volume 2\%. University of Chicago Press.

Auerbach, A. and Gorodnichenko, Y. (2012). Measuring the Output Responses to Fiscal Policy. American Economic Journal: Economic Policy, 4(2):1-27.

Auerbach, A. J. and Gorodnichenko, Y. (2013). Fiscal Multipliers in Recession and Expansion. In Alesina, A. and Giavazzi, F., editors, Fiscal Policy after the Financial Crisis, pages 63-98. University of Chicago Press.

Bachmann, R. and Sims, E. R. (2012). Confidence and the Transmission of Government Spending Shocks. Journal of Monetary Economics, 59(3):235-249.

Baker, S., Bloom, N., and Davis, S. (2013). Measuring Economic Policy Uncertainty. Working Paper 13-02, Chicago Booth Research Paper.

Barro, R. J. and Redlick, C. J. (2011). Macroeconomic Effects from Government Purchases and Taxes. The Quarterly Journal of Economics, 126(1):51-102.

Bertola, G. and Drazen, A. (1993). Trigger Points and Budget Cuts: Explaining the Effects of Fiscal Austerity. American Economic Review, 83(1):11-26.

Bi, H., Leeper, E. M., and Leith, C. (2013). Uncertain Fiscal Consolidations. The Economic Journal, 123(566):F31-F63.

Blanchard, O. and Perotti, R. (2002). An Empirical Characterization of the Dynamic Effects of Changes in Government Spending and Taxes on Output. the Quarterly Journal of Economics, 117(4):1329-1368.

Bloom, N. (2009). The Impact of Uncertainty Shocks. Econometrica, 77(3):623-685.

Bloom, N. (2014). Fluctuations in Uncertainty. The Journal of Economic Perspectives, $28(2): 153-175$.

Bloom, N., Bond, S., and Reenen, J. V. (2007). Uncertainty and Investment Dynamics. Review of Economic Studies, 74(2):391-415.

Bloom, N., Floetotto, M., Jaimovich, N., Saporta-Eksten, I., and Terry, S. J. (2012). Really Uncertain Business Cycles. NBER Working Papers 18245, National Bureau of Economic Research, Inc. 
Bognanni, M. (2012). An Empirical Analysis of Time-Varying Fiscal Multipliers. Working paper, Working Paper. University of Pennsylvania.

Brückner, M. and Tuladhar, A. (2013). Local Government Spending Multipliers and Financial Distress: Evidence from Japanese Prefectures. The Economic Journal.

Burnside, C., Eichenbaum, M., and Fisher, J. (2004). Fiscal Shocks and their Consequences. Journal of Economic Theory, 115:89-117.

Caggiano, G., Castelnuovo, E., Colombo, V., and Nodari, G. (2015). Estimating Fiscal Multipliers: News From A Non-linear World. The Economic Journal, 125(584):746776.

Christiano, L., Eichenbaum, M., and Rebelo, S. (2011). When Is the Government Spending Multiplier Large? Journal of Political Economy, 119(1):pp. 78-121.

Corsetti, G., Kuester, K., Meier, A., and Müller, G. J. (2013). Sovereign Risk, Fiscal Policy, and Macroeconomic Stability. The Economic Journal, 123(566):F99-F132.

Fazzari, S. M., Morley, J., and Panovska, I. (2012). State-Dependent Effects of Fiscal Policy. Australian School of Business Research Paper, 27.

Fernández-Villaverde, J., Gordon, G., Guerrón-Quintana, P. A., and Rubio-Ramírez, J. (2012). Nonlinear Adventures at the Zero Lower Bound. Working paper, National Bureau of Economic Research.

Fernández-Villaverde, J., Guerrón-Quintana, P. A., Kuester, K., and Rubio-Ramírez, J. (2011). Fiscal Volatility Shocks and Economic Activity. Working paper, National Bureau of Economic Research.

Francis, N. and Ramey, V. A. (2009). Measures of per Capita Hours and Their Implications for the Technology-Hours Debate. Journal of Money, Credit and Banking, 41(6):1071-1097.

Giavazzi, F. and Pagano, M. (1990). Can Severe Fiscal Contractions be Expansionary? Tales of Two Small European Countries. In NBER Macroeconomics Annual 1990, Volume 5, pages 75-122. MIT Press.

Gonçalves, S. and Kilian, L. (2004). Bootstrapping Autoregressions with Conditional Heteroskedasticity of Unknown Form. Journal of Econometrics, 123(1):89-120.

Hall, R. E. (2010). By How Much Does GDP Rise If the Government Buys More Output? Brookings Papers on Economic Activity: Fall 2009, page 183.

Jordà, O. (2005). Estimation and Inference of Impulse Responses by Local Projections. American economic review, pages 161-182.

Mertens, K. and Ravn, M. O. (2013). The Dynamic Effects of Personal and Corporate Income Tax Changes in the United States. American Economic Review, 103(4):121247. 
Mertens, K. and Ravn, M. O. (2014). Fiscal Policy in an Expectations-Driven Liquidity Trap. The Review of Economic Studies, 81(4):1636-1667.

Michaillat, P. (2014). A Theory of Countercyclical Government Multiplier. American Economic Journal: Macroeconomics, 6(1).

Mittnik, S. and Semmler, W. (2012). Regime Dependence of the Fiscal Multiplier. Journal of Economic Behavior \& Organization, 83(3):502-522.

Mountford, A. and Uhlig, H. (2009). What Are the Effects of Fiscal Policy Shocks? Journal of Applied Econometrics, 24(6):960-992.

Owyang, M. T., Ramey, V. A., and Zubairy, S. (2013). Are Government Spending Multipliers Greater during Periods of Slack? Evidence from Twentieth-Century Historical Data. American Economic Review, 103(3):129-34.

Parker, J. A. (2011). On Measuring the Effects of Fiscal Policy in Recessions. The Journal of Economic Literature, 49(3):703-18.

Perotti, R. (2004). Estimating the Effects of Fiscal Policy in OECD Countries. IGIER Working Paper No. 276.

Ramey, V. (2011a). Identifying Government Spending Shocks: It's all in the Timing. The Quarterly Journal of Economics, 126(1):1.

Ramey, V. and Shapiro, M. (1998). Costly Capital Reallocation and the Effects of Government Spending. In Carnegie-Rochester Conference Series on Public Policy, volume 48, pages 145-194. Elsevier.

Ramey, V. A. (2011b). Can Government Purchases Stimulate the Economy? Journal of Economic Literature, 49(3):673-685.

Ramey, V. A. and Zubairy, S. (2014). Government Spending Multipliers in Good Times and in Bad: Evidence from US Historical data. Working paper, National Bureau of Economic Research.

Romer, C. and Romer, D. (2010). The Macroeconomic Effects of Tax Changes: Estimates Based on a New Measure of Fiscal Shocks. The American Economic Review, 100(3):763-801. 
Figure 1: Periods of HU and R between 1948 Q1 and 2007 Q4

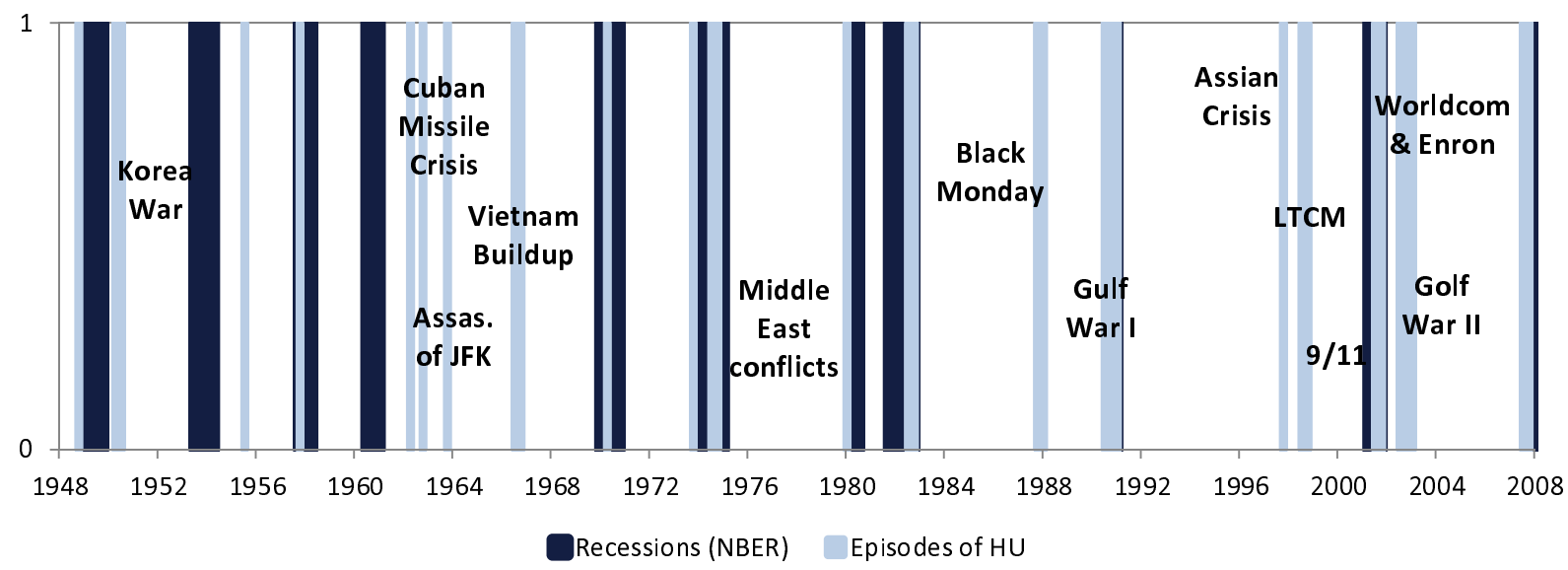


Figure 2: Responses in the linear model (SVAR identification)
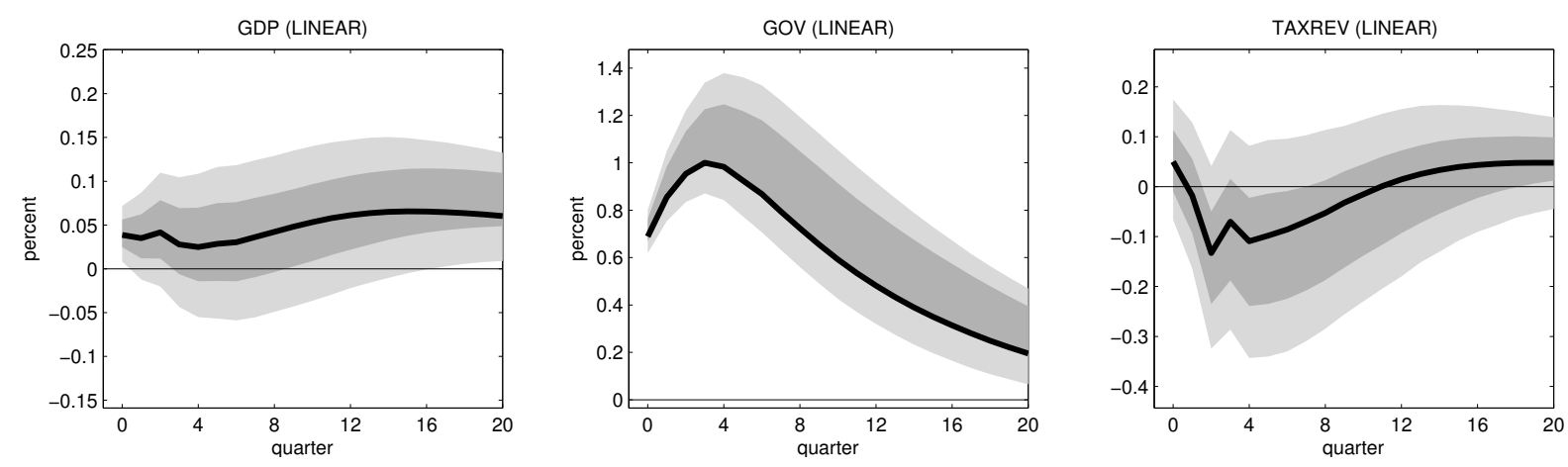

Responses to a government spending shock (identified with exclusion restrictions) in a linear model. $68 \%$ and $95 \%$ confidence bands computed with a non-parametric bootstrap. 
Figure 3: Responses during times of LU and HU (SVAR identification)
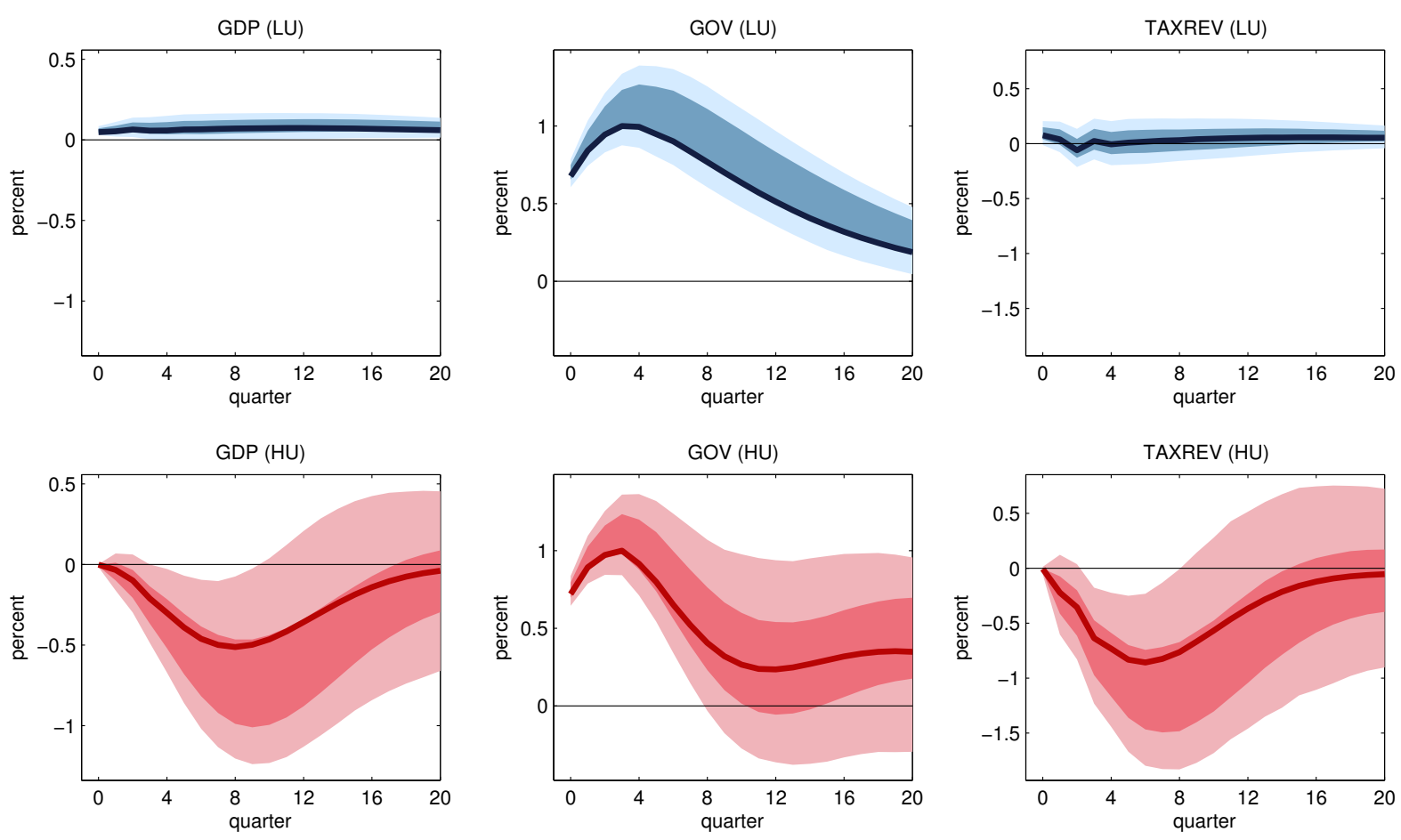

The top panel (in blue) shows responses to a government spending shock (identified with exclusion restrictions) during times of low uncertainty. The bottom panel (in red) shows responses during times of high uncertainty. The $68 \%$ and $95 \%$ confidence bands are computed using a non-parametric bootstrap. 
Figure 4: Responses during times of B and R (SVAR identification)
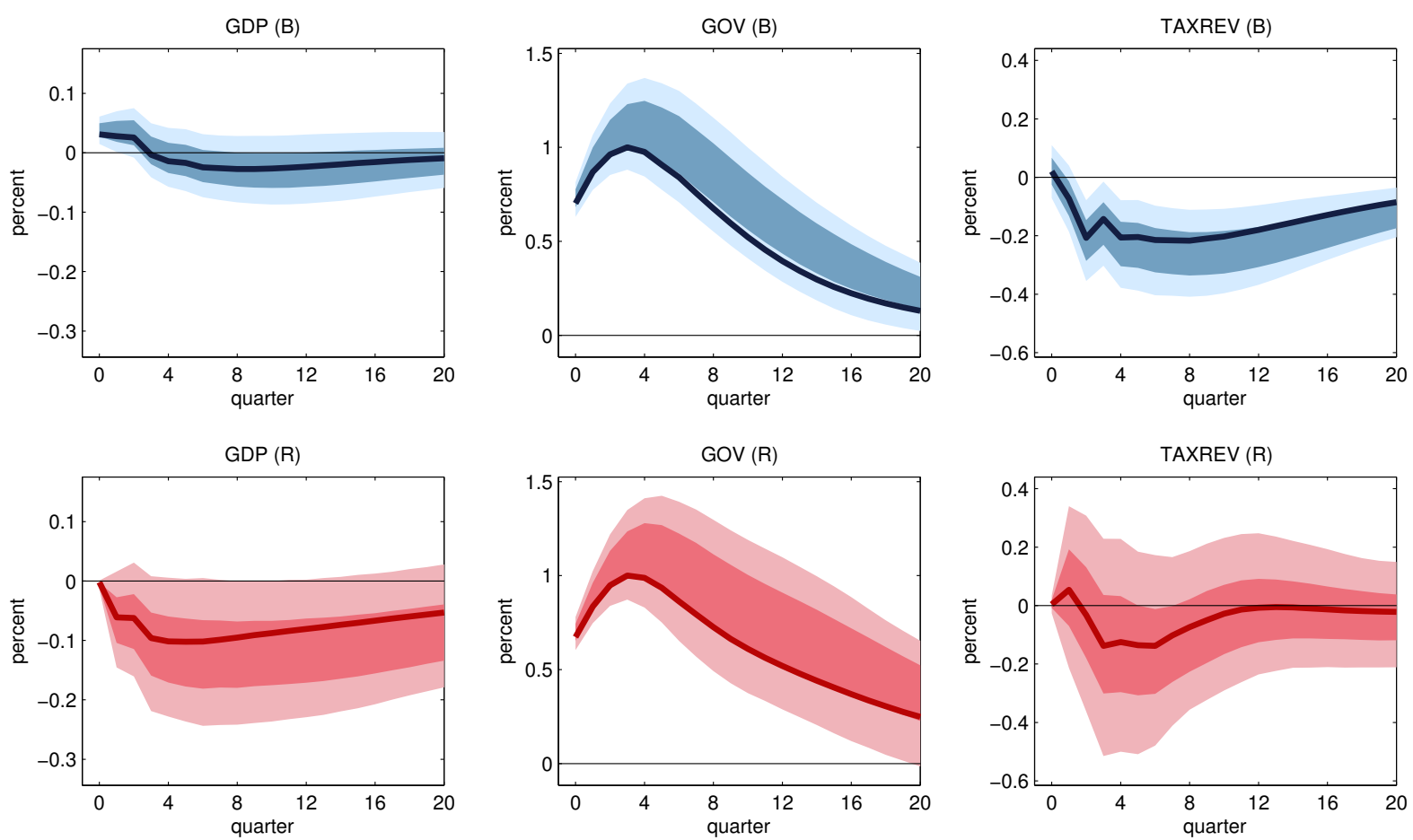

The top panel (in blue) shows responses to a government spending shock (identified with exclusion restrictions) during times of boom. The bottom panel (in red) shows responses during times of recession. The $68 \%$ and $95 \%$ confidence bands are computed using a non-parametric bootstrap. 
Figure 5: Responses in the linear model (narrative identification)
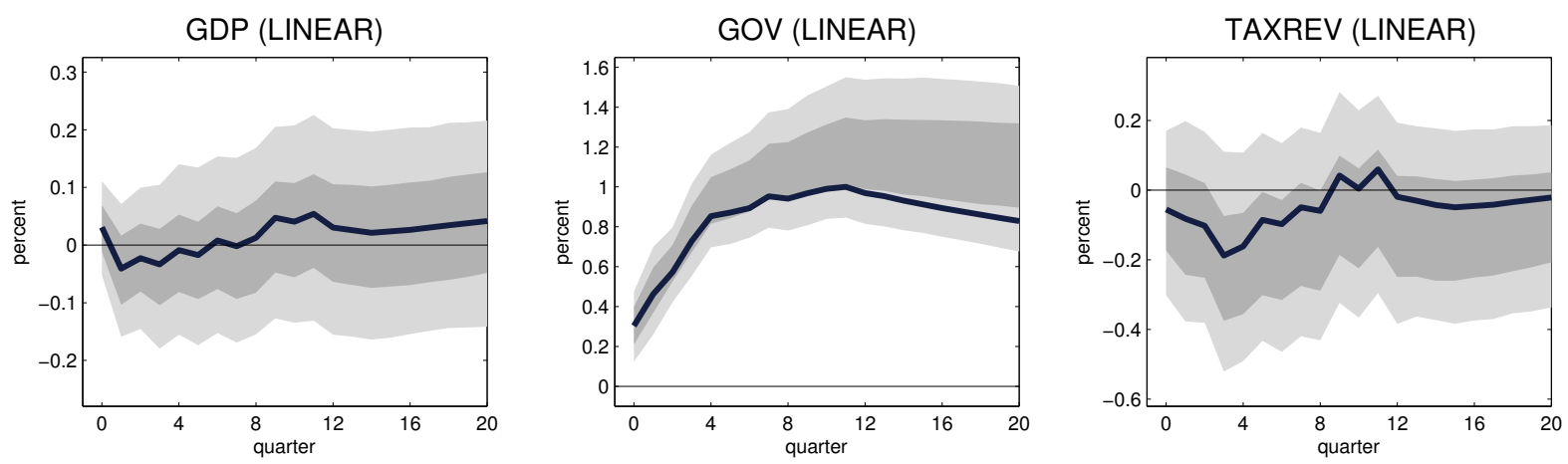

Responses to a government spending shock (identified from narrative accounts of defence spending) in a linear model. The $68 \%$ and $95 \%$ confidence bands are computed using a non-parametric bootstrap. 
Figure 6: Responses during times of LU and HU (narrative identification)
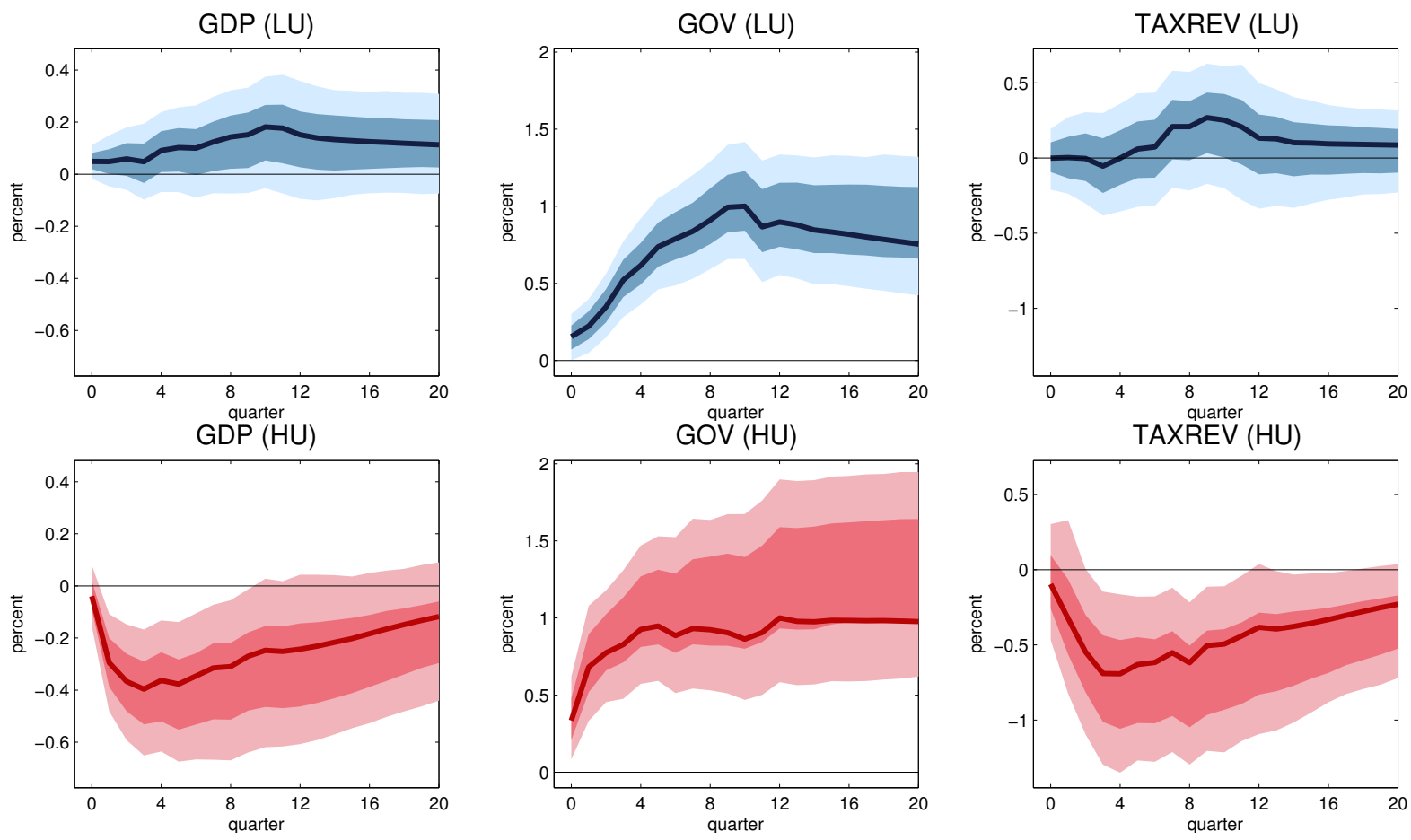

The top panel (in blue) shows responses to a government spending shock (identified from narrative accounts of defence spending) during times of low uncertainty. The bottom panel (in red) shows responses during times of high uncertainty. The $68 \%$ and $95 \%$ confidence bands are computed using a non-parametric bootstrap. 
Figure 7: Responses during times of B and R (narrative identification)
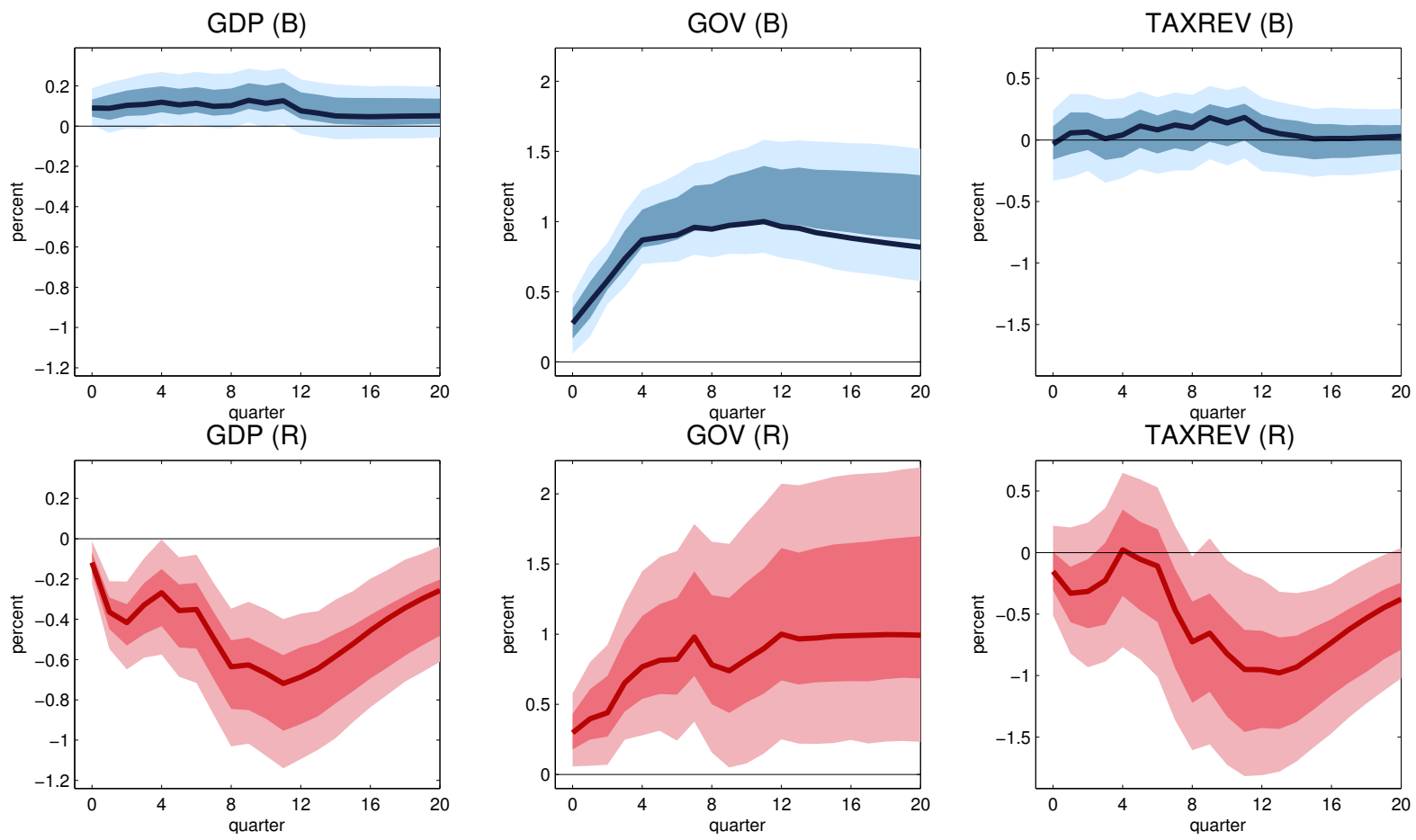

The top panel (in blue) shows responses to a government spending shock (identified from narrative accounts of defence spending) during times of boom. The bottom panel (in red) shows responses during times of recession. The $68 \%$ and $95 \%$ confidence bands are computed using a non-parametric bootstrap. 
Figure 8: Measures of confidence during times of HU and LU (narrative identification)
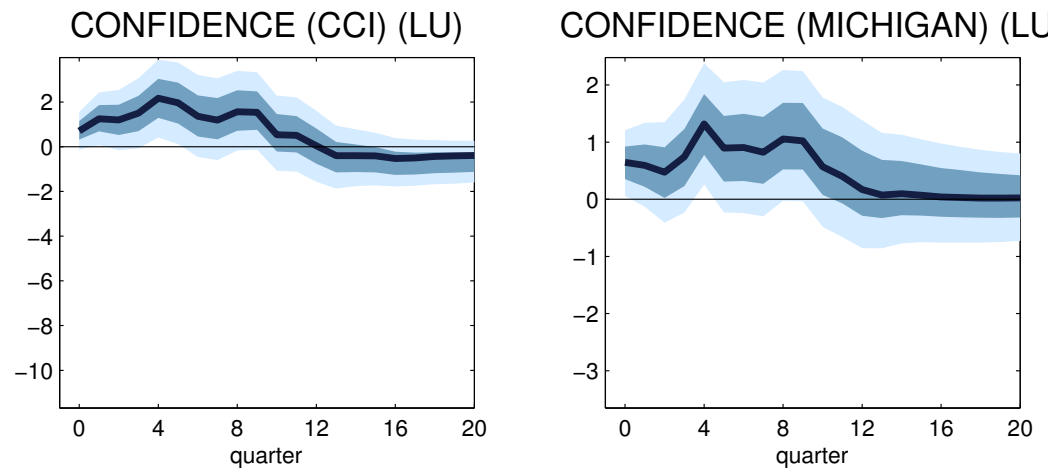

INDUSTRIAL CONF. (LU)
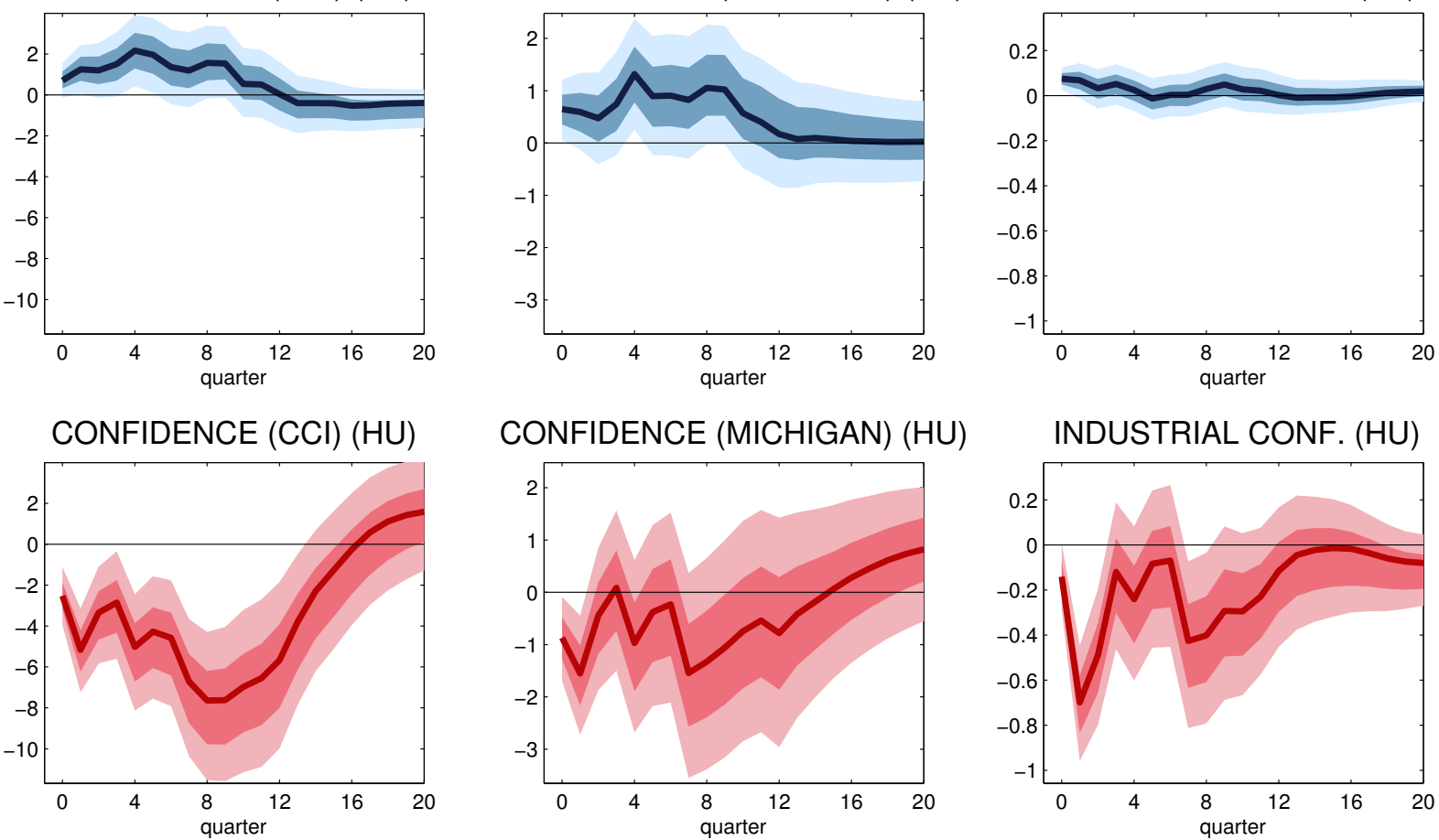

INDUSTRIAL CONF. (HU)

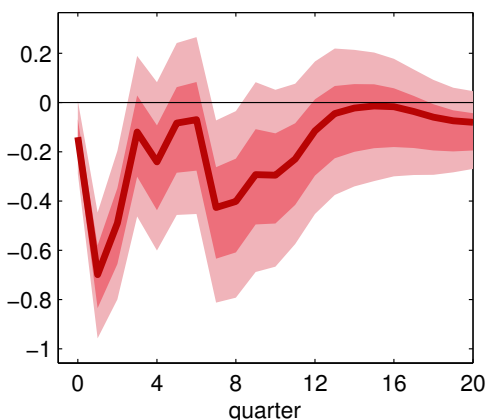

The top panel (in blue) shows the responses of different measures of consumers' and firms' confidence to a government spending shock (identified from narrative accounts of defence spending) during times of low uncertainty. The measures of confidence include the Consumer Confidence Index (CCI) provided by the Conference Board (data start in 1967 Q1), the Index of Consumer Sentiment provided by the University of Michigan (data start in 1960 Q1) and the Business Conditions Indicator from the OECD (data start in 1950 Q1). The bottom panel (in red) shows responses during times of high uncertainty. The $68 \%$ and $95 \%$ confidence bands are computed using a non-parametric bootstrap. 
Figure 9: Further responses during times of HU and LU (narrative identification)
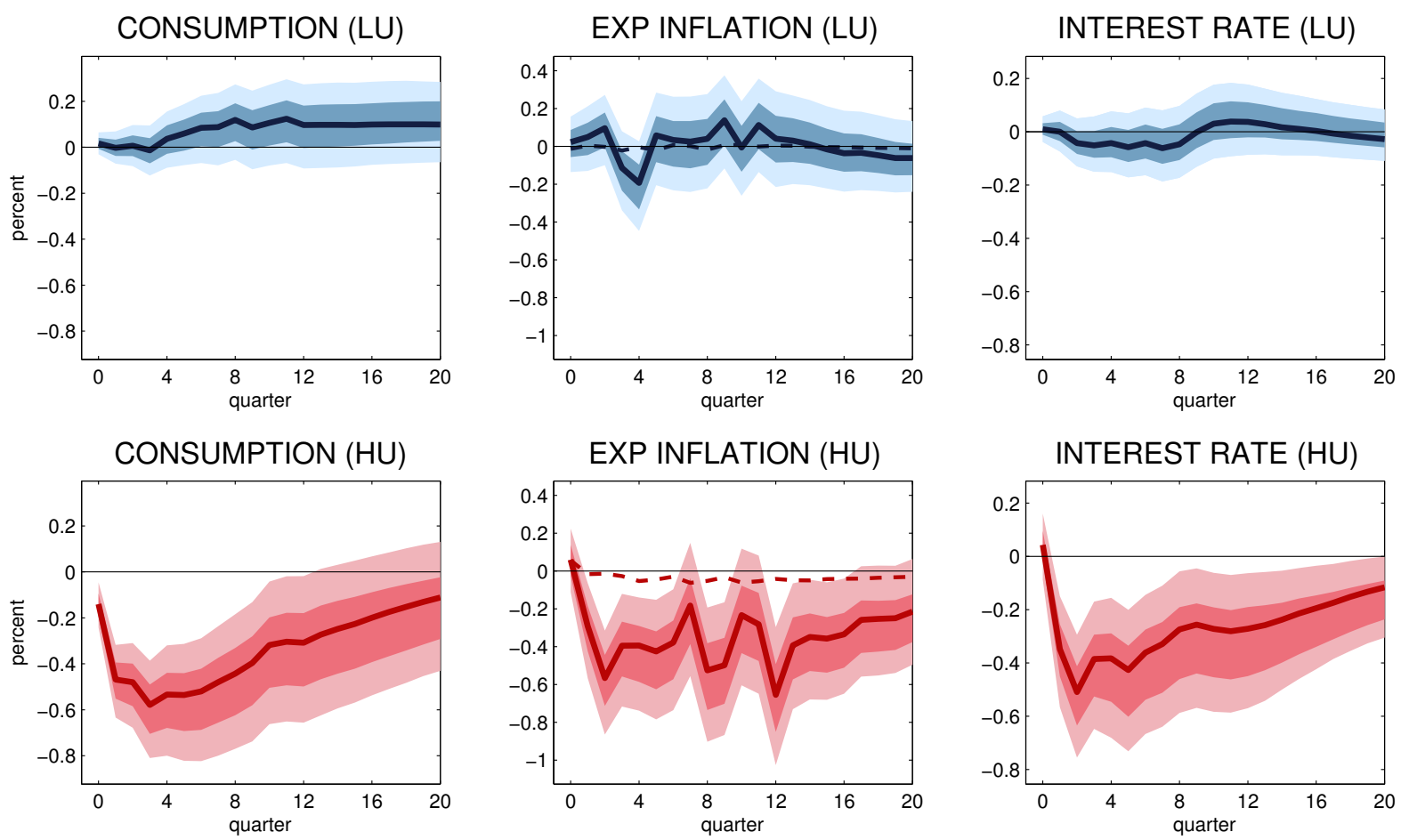

The top panel (in blue) shows the responses of different measures of consumers' confidence to a government spending shock (identified from narrative accounts of defence spending) during times of low uncertainty. The broken lines represent realised inflation, as measured by the Consumer Price Index. Expected inflation is measured by the median inflation forecast over the next 12 months from the Survey of Consumers (University of Michigan). Interest rates are measured using the three-month Treasury bill. The bottom panel (in red) shows the responses during times of high uncertainty. The $68 \%$ and $95 \%$ confidence bands are computed using a non-parametric bootstrap. 
Figure 10: Responses during times of $\mathrm{R}$ and B using the Auerbach and Gorodnichenko (2012) framework and a two-sided MA filter
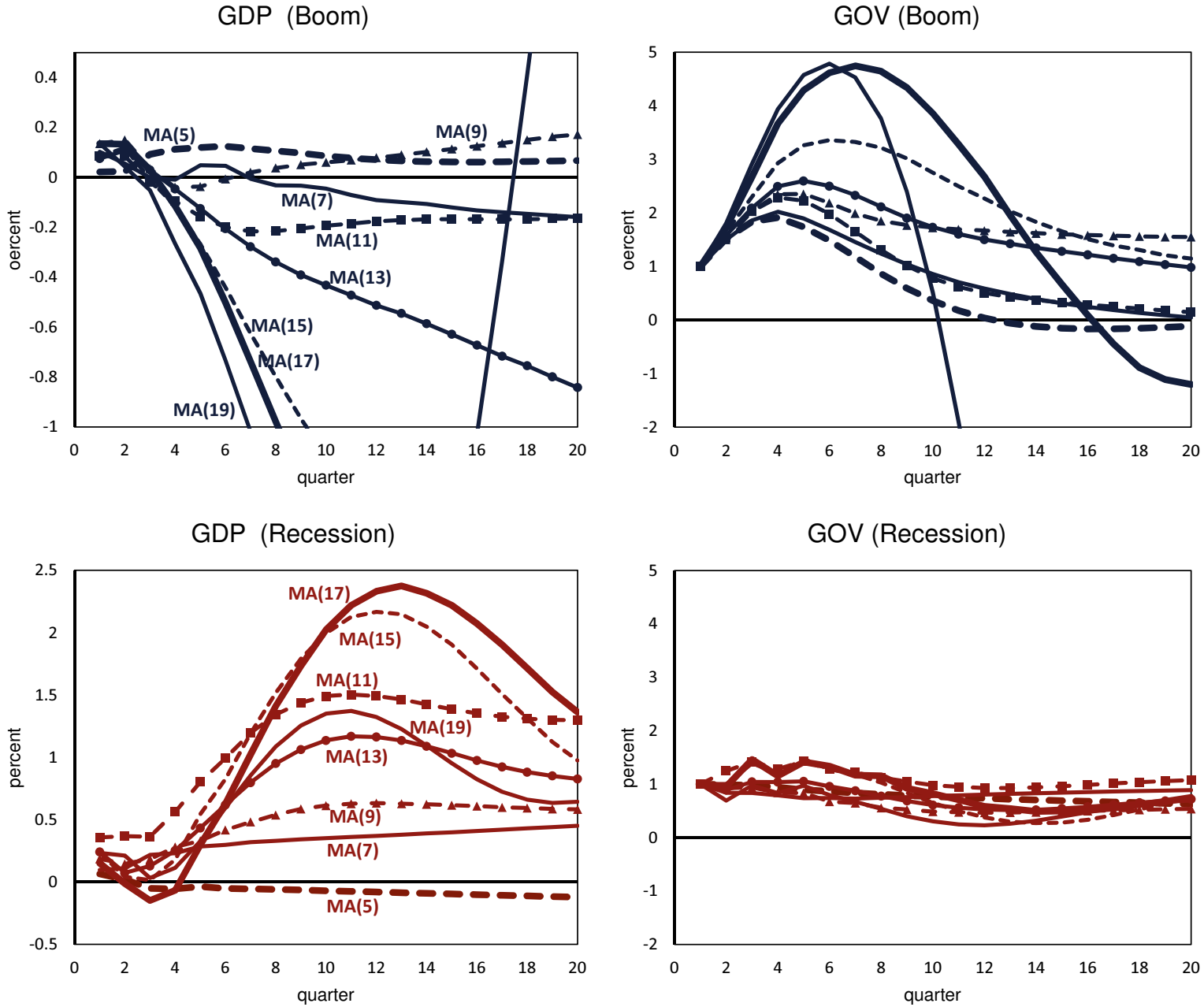

The top panel (in blue) shows responses to a government spending shock during times of boom. The bottom panel (in red) shows responses during times of recession. Note that the graphs in the left column have a different scale to facilitate their readability. The responses are computed using the strategy described in Amerbach and Gorodnichenko (2012) but with variations in the size of the centred moving average of the growth rate of real GDP used to provide information about changes in the regime. 
Figure 11: Responses during times of $\mathrm{R}$ and $\mathrm{B}$ using the Auerbach and Gorodnichenko (2012) framework and a one-sided MA filter
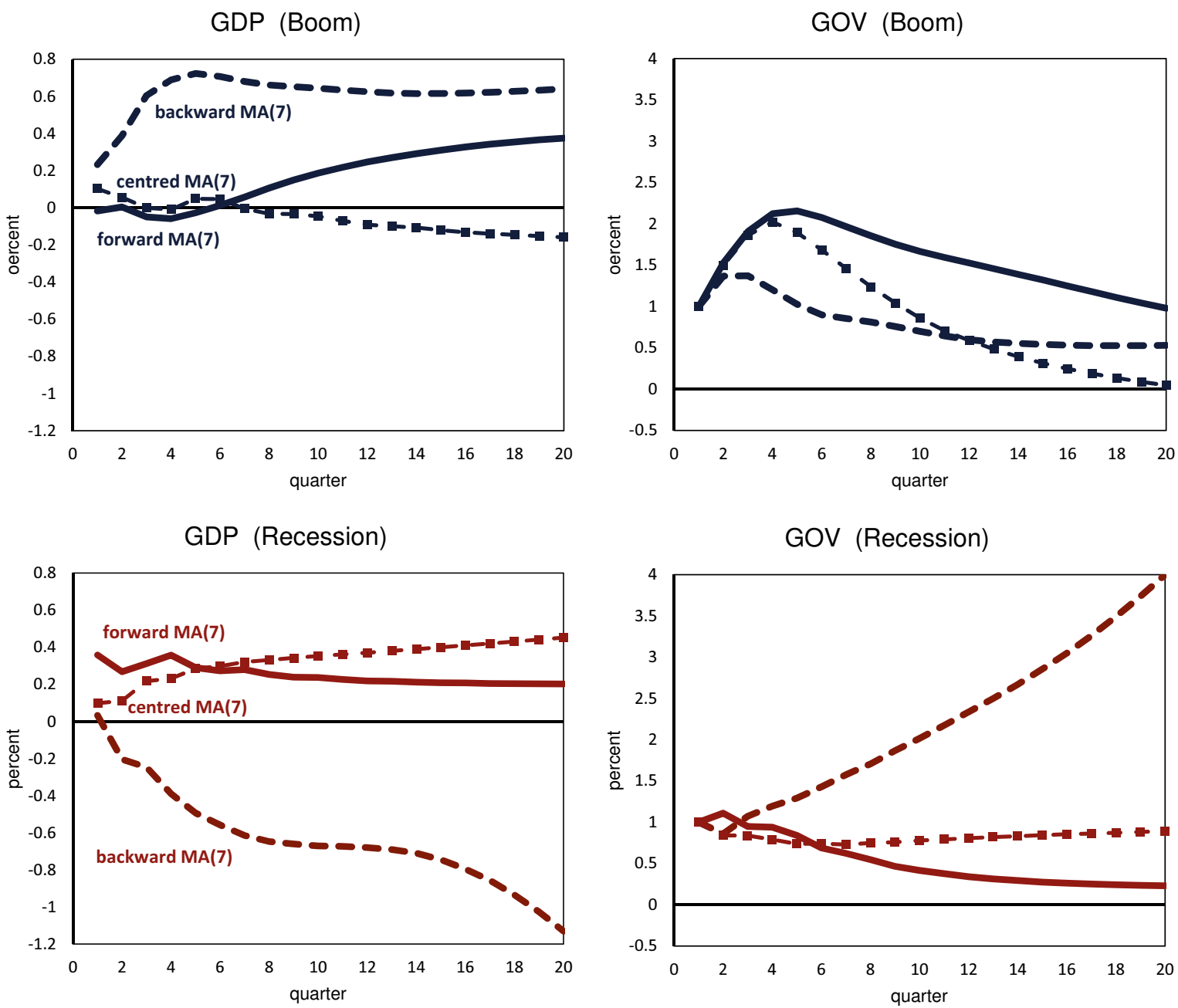

The top panel (in blue) shows responses to a government spending shock during times of boom. The bottom panel (in red) shows responses during times of recession. The responses are computed using the strategy described in Auerbach and Gorodnichenko (2012) but with variations made to the centring of the moving average (MA) of the growth rate of real GDP used to provide information about changes in the regime. Forward MA(7) is a one-sided MA filter of order 7 using future information only; backward MA(7) is a one-sided MA filter of order 7 using exclusively past information. 
Figure 12: Responses under alternative definition of HU events (SVAR identification)
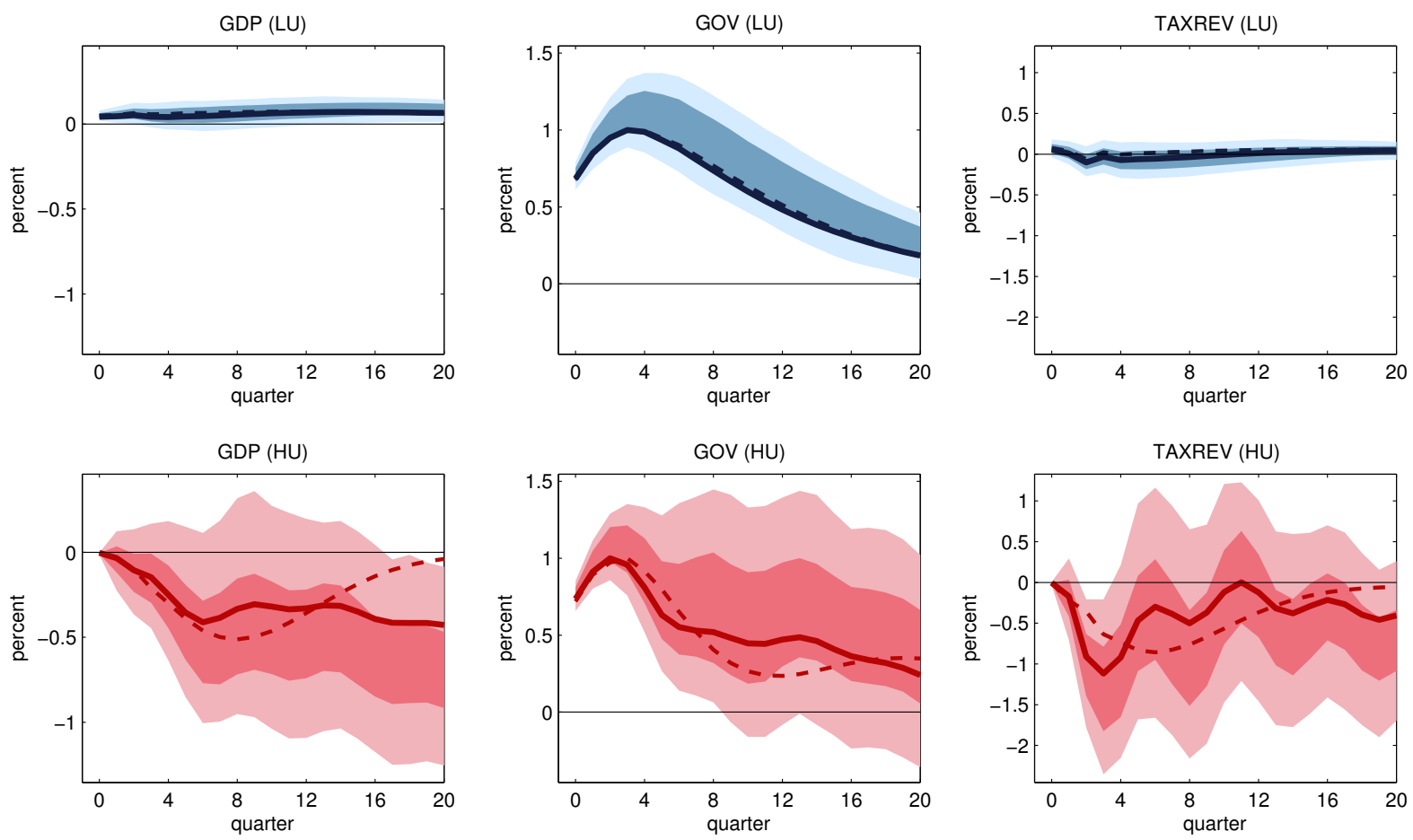

The top panel (in blue) shows responses to a government spending shock (identified from exclusion restrictions) during times of low uncertainty. The bottom panel (in red) shows responses during times of high uncertainty. The solid line plots the point estimates for the alternative definition of HU events. The dashed lined plots the point estimates for the benchmark definition used in Section 2 . The $68 \%$ and $95 \%$ confidence bands are computed using a non-parametric bootstrap. 
Figure 13: Responses under alternative definition of HU events (Narrative identification)
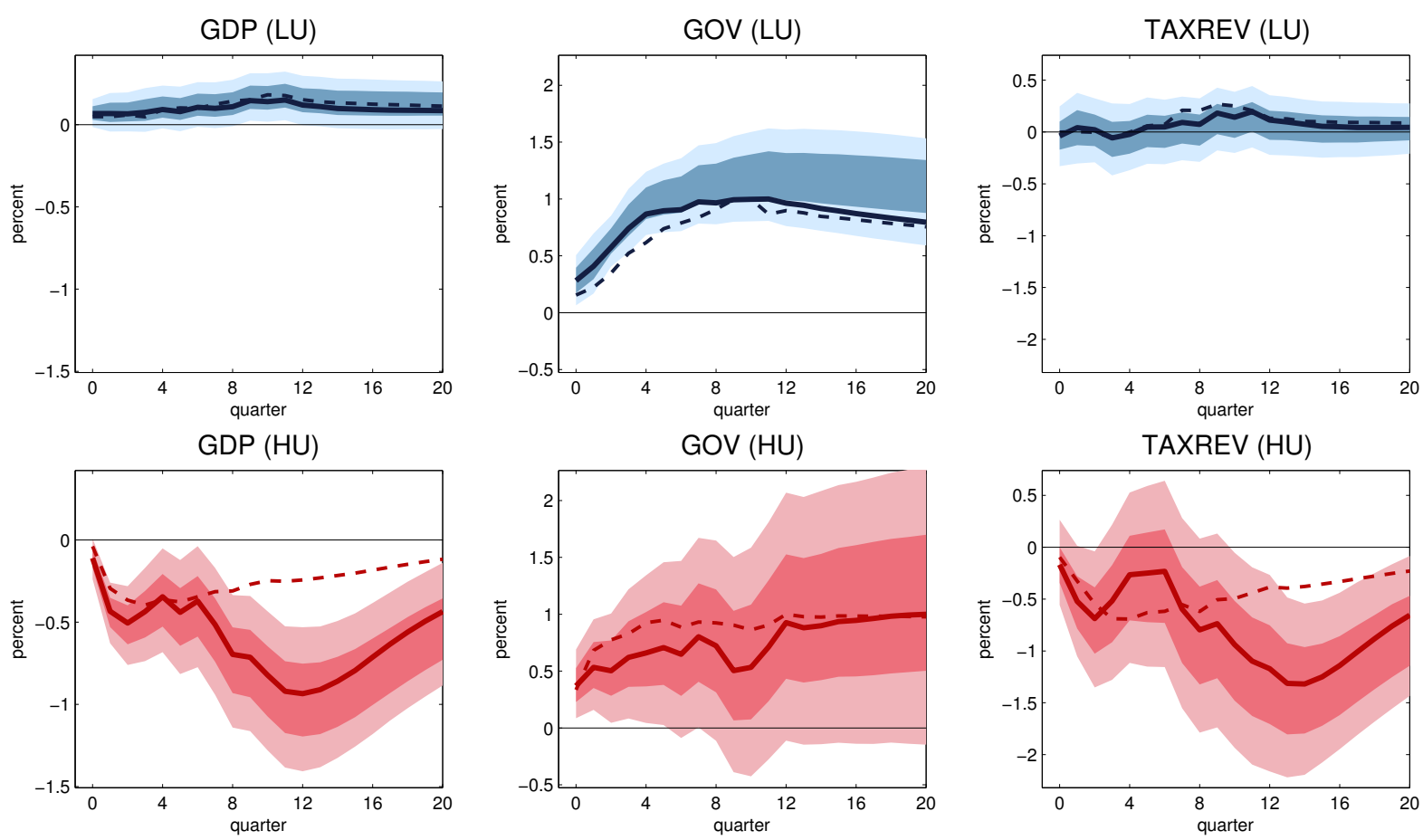

The top panel (in blue) shows responses to a government spending shock (identified from narrative accounts of defence spending) during times of low uncertainty. The bottom panel (in red) shows responses during times of high uncertainty. The solid line plots the point estimates for the alternative definition of HU events. The dashed lined plots the point estimates for the benchmark definition used in Section 叉. The $68 \%$ and $95 \%$ confidence bands are computed using a non-parametric bootstrap. 
Figure 14: Responses during times of $\mathrm{LU}$ and $\mathrm{HU}$ computed using local projections (SVAR identification)
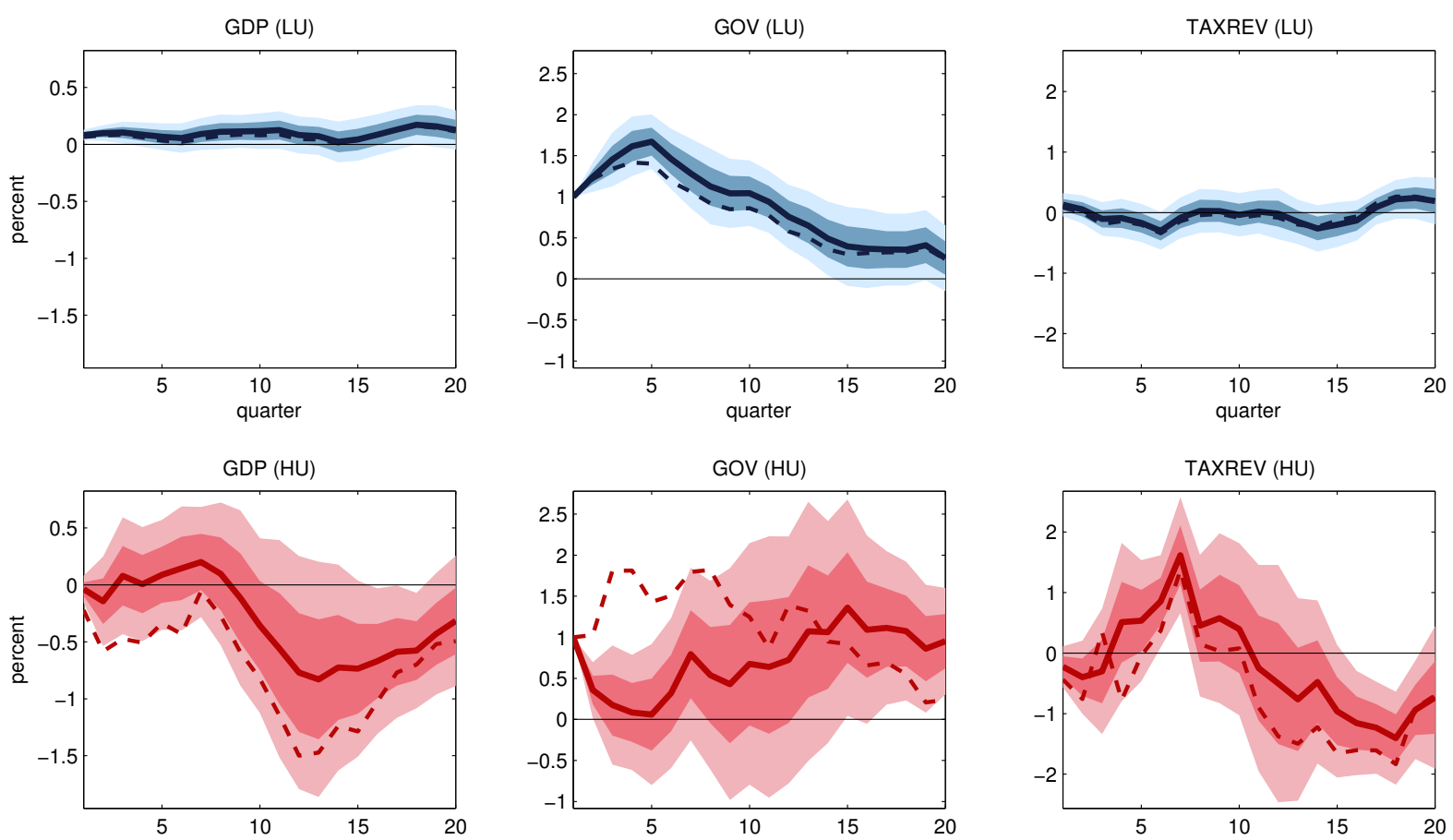

The top panel (in blue) shows responses to a government spending shock (identified using exclusion restrictions) during times of low uncertainty. The bottom panel (in red) shows responses during times of high uncertainty. Responses are computed using the local projection method as described in Tordà (20105). The $68 \%$ and $95 \%$ confidence bands are computed using a non-parametric bootstrap. 
Figure 15: Responses during times of LU and HU, computed using local projections (narrative identification)
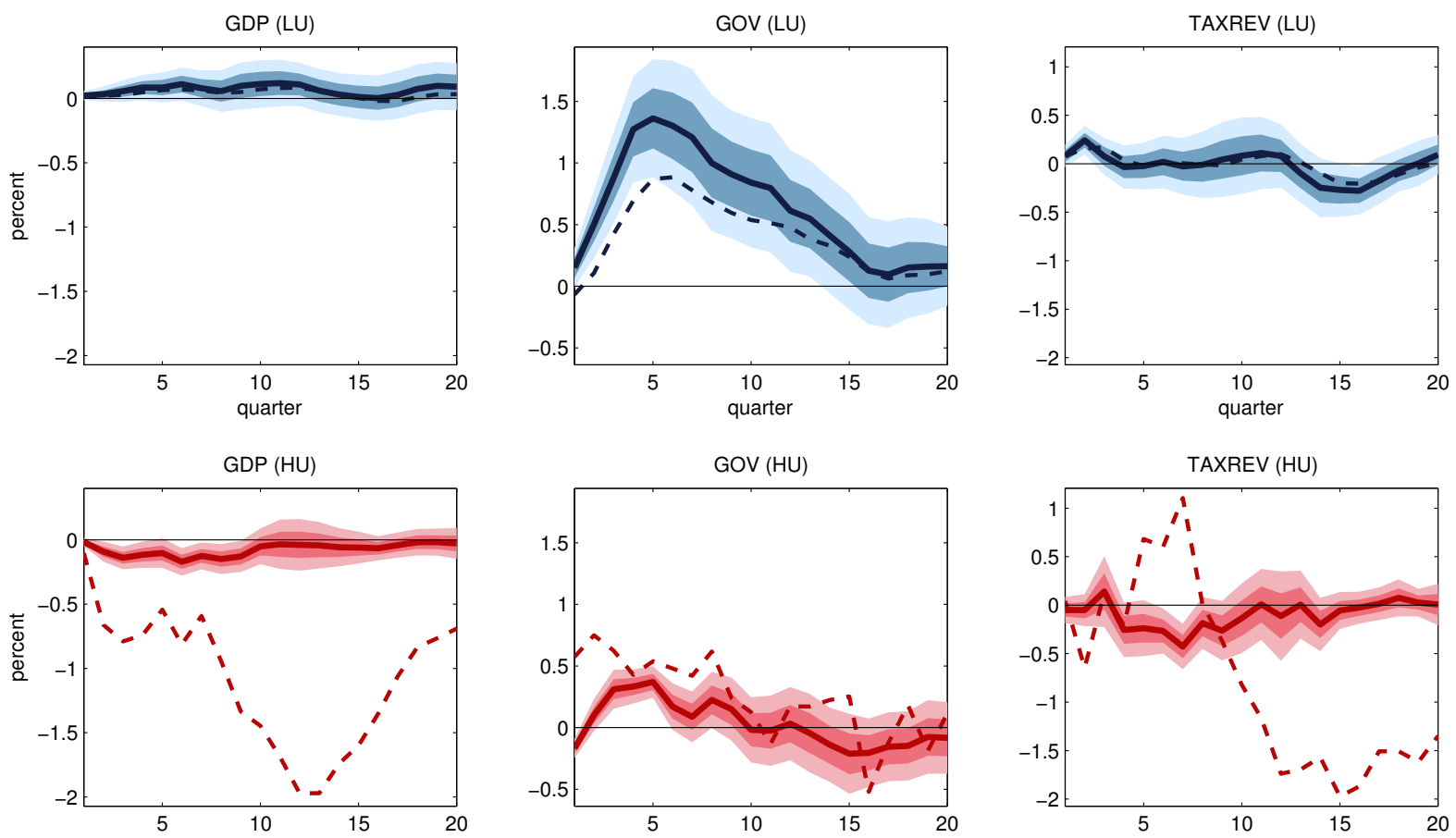

The top panel (in blue) shows responses to a government spending shock (identified from narrative accounts of defence spending) during times of low uncertainty. The bottom panel (in red) shows responses during times of high uncertainty. The responses are computed using the local projection method as described in Jordà (20105). The $68 \%$ and $95 \%$ confidence bands are computed using a non-parametric bootstrap. 
Figure 16: Responses during times of B and R, computed using local projections (SVAR identification)
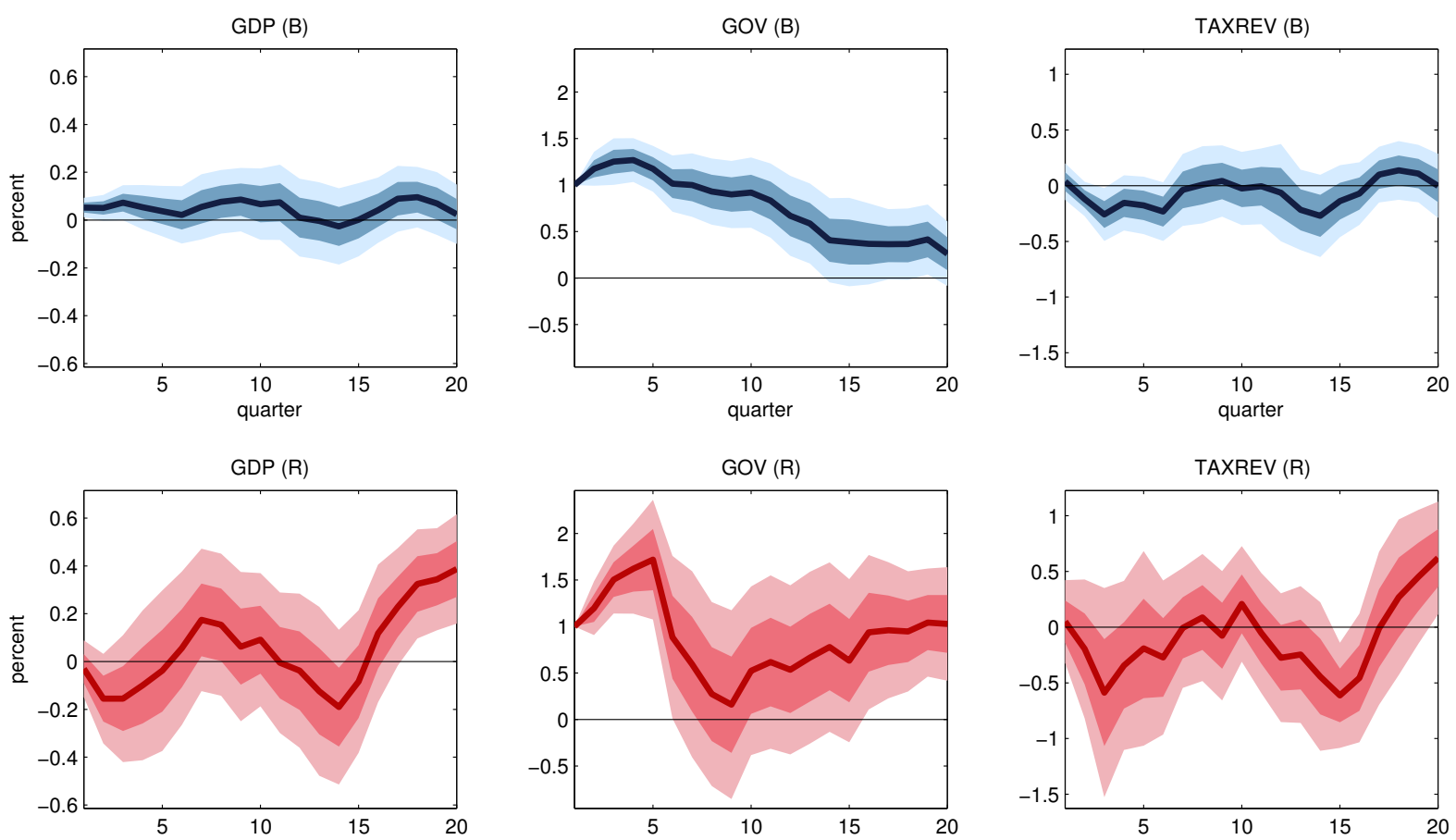

The top panel (in blue) shows responses to a government spending shock (identified using exclusion restrictions) during times of boom. The bottom panel (in red) shows responses during times of recession. The responses are computed using the local projection method as described in Dordă (2005). The $68 \%$ and $95 \%$ confidence bands are computed using a non-parametric bootstrap. 
Figure 17: Responses during times of $\mathrm{B}$ and $\mathrm{R}$, computed using local projections (narrative identification)
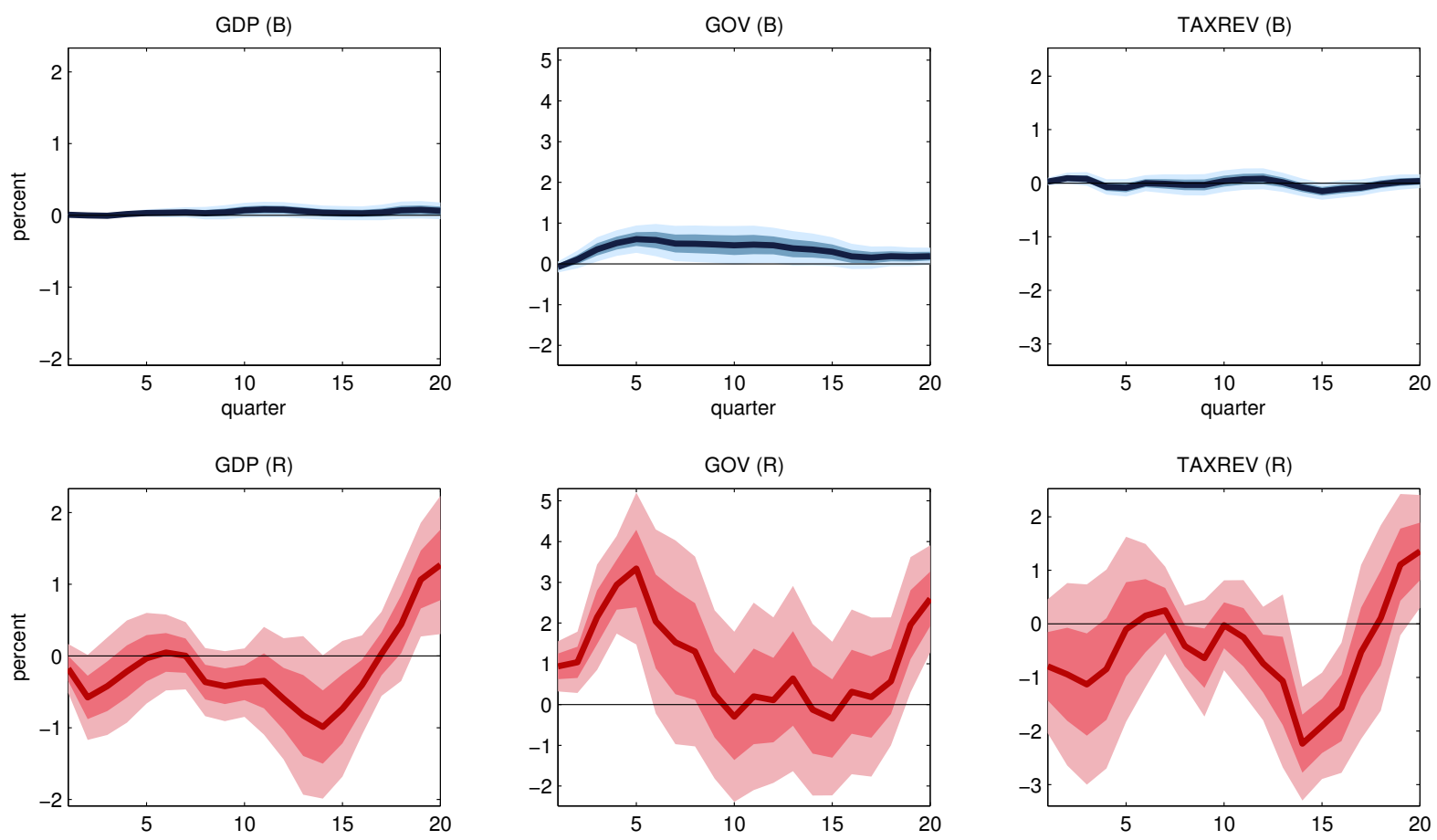

The top panel (in blue) shows responses to a government spending shock (identified from narrative accounts of defence spending) during times of boom. The bottom panel (in red) shows responses during times of recession. The responses are computed using the local projection method as described in Jordà (20105). The $68 \%$ and $95 \%$ confidence bands are computed using a non-parametric bootstrap. 
Figure 18: Responses during times of LU and HU (proxy identification)
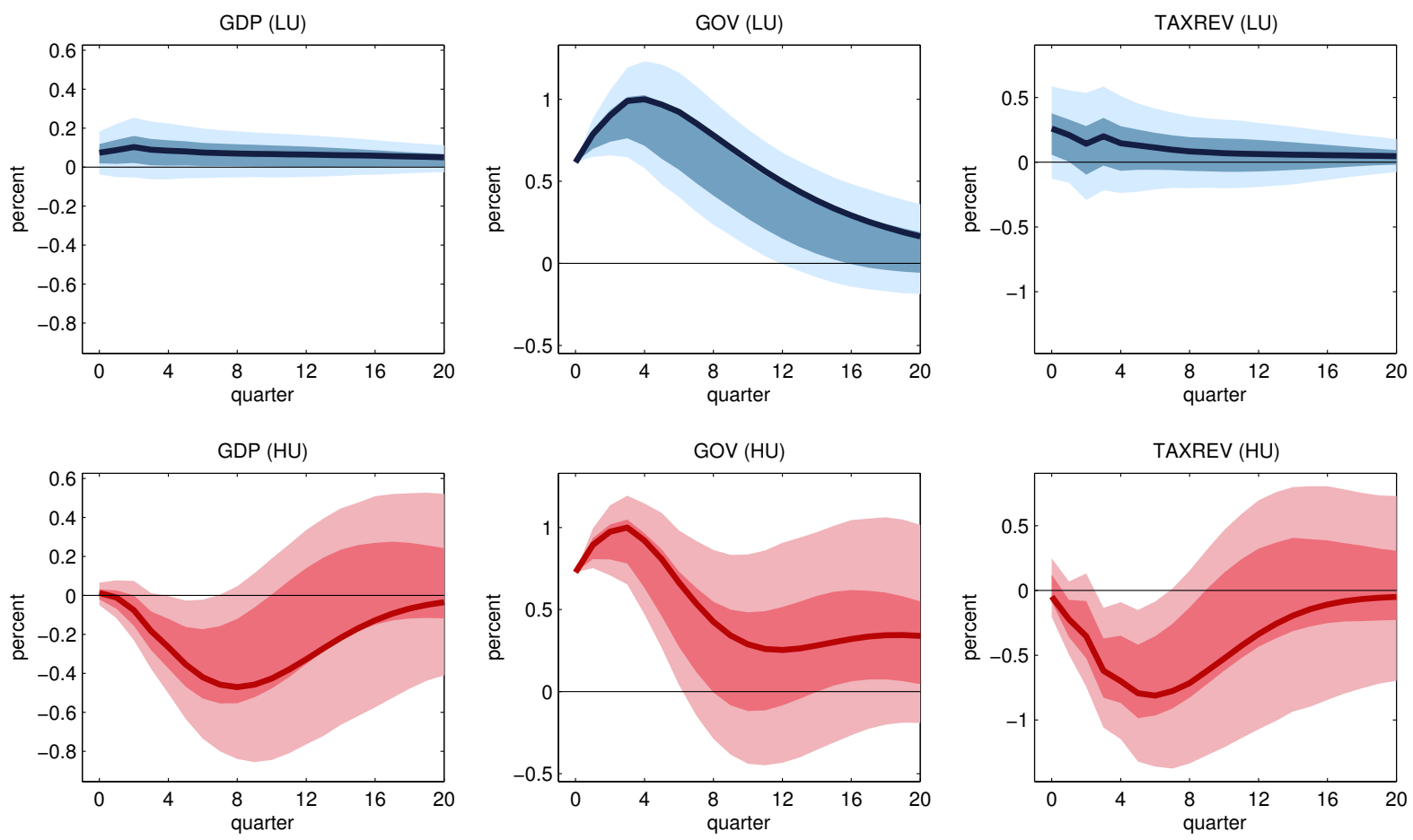

The top panel (in blue) shows responses to a government spending shock during times of low uncertainty. The bottom panel (in red) shows responses during times of high uncertainty. Government spending shocks are identified using the Ramey (20lla) news about defence spending as a proxy for the true structural shocks. The $68 \%$ and $95 \%$ confidence bands are computed using the Gonçalves and Kilian (2004) wild bootstrap. 
Figure 19: Proxy identification, $\mathrm{R}$ versus $\mathrm{B}$
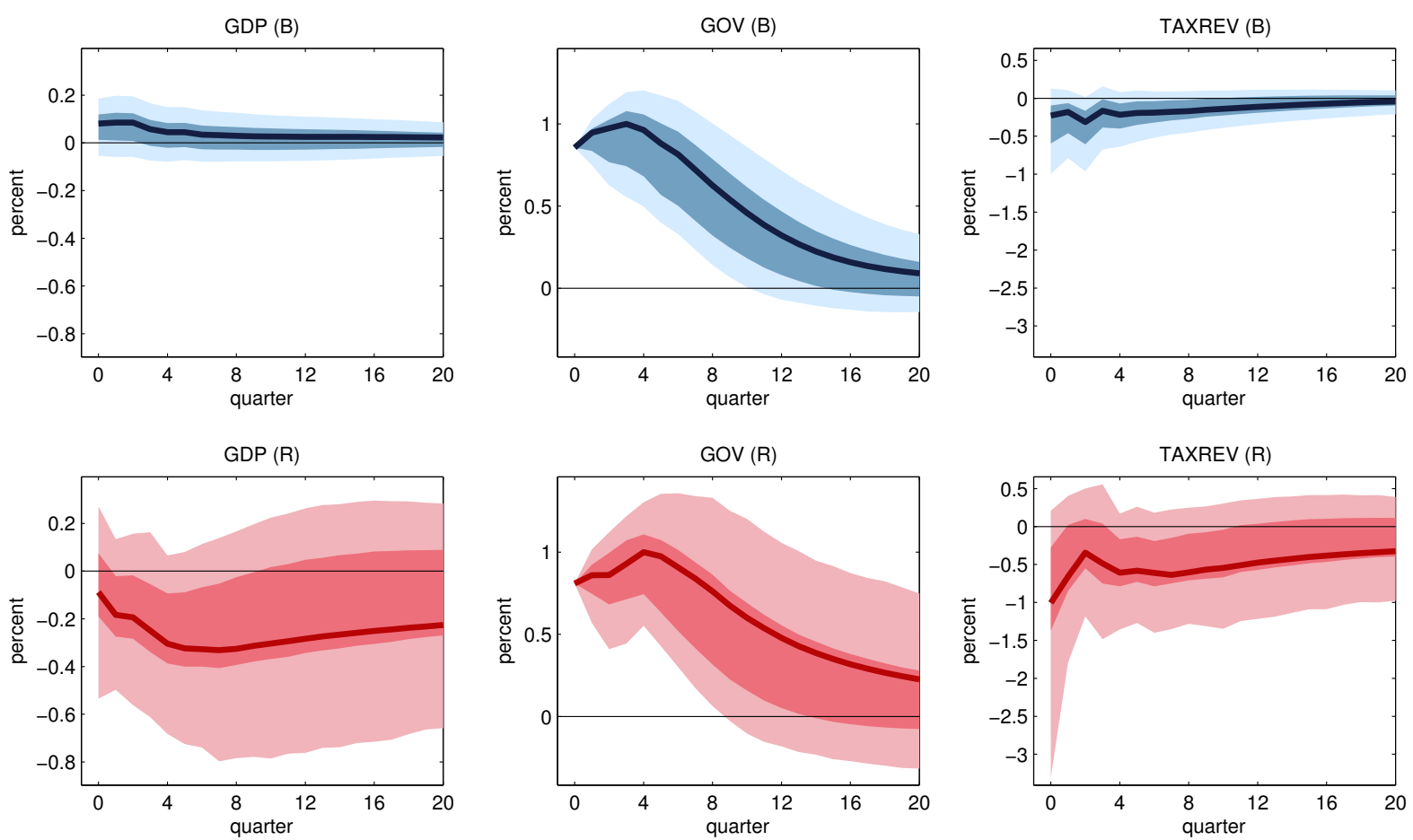

The top panel (in blue) shows responses to a government spending shock during times of B. The bottom panel (in red) shows responses during times of R. Government spending shocks are identified using the Ramey (20lal) news about defence spending as a proxy for the true structural shocks. The $68 \%$ and $95 \%$ confidence bands are computed using the Gonçalves and Kilian (2004) wild bootstrap. 
Figure 20: Responses in the linear case (alternative narrative identification)
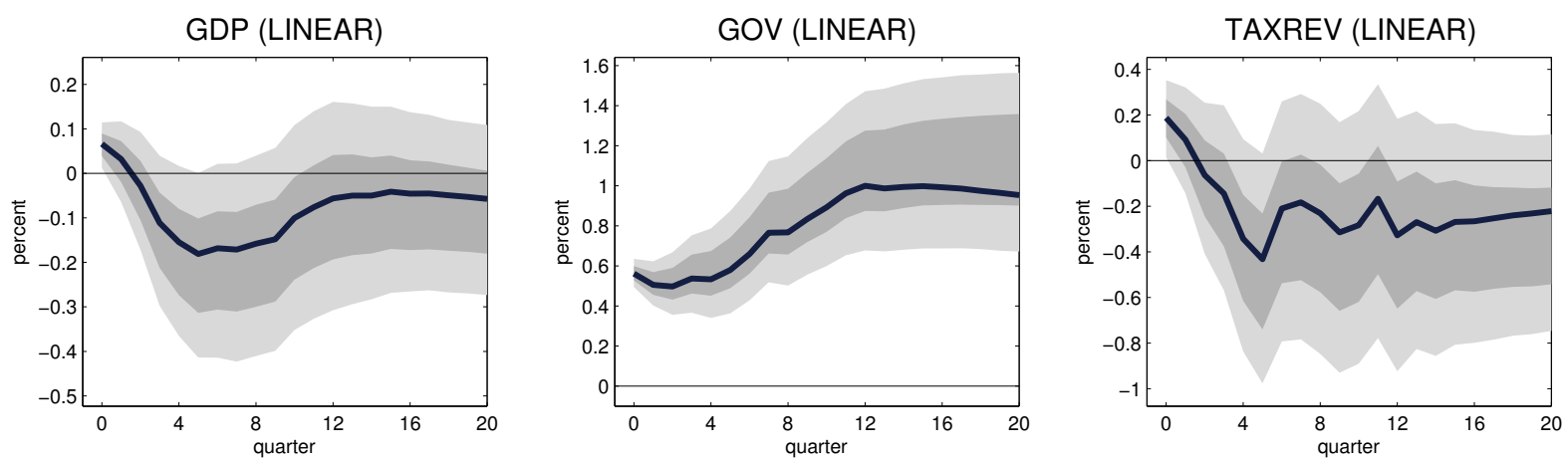

Responses in the linear model after a government spending shock identified using Ramey (201la) defence spending forecast errors. The $68 \%$ and $95 \%$ confidence bands are computed using a nonparametric bootstrap. 
Figure 21: Responses during periods of HU and LU (alternative narrative identification)
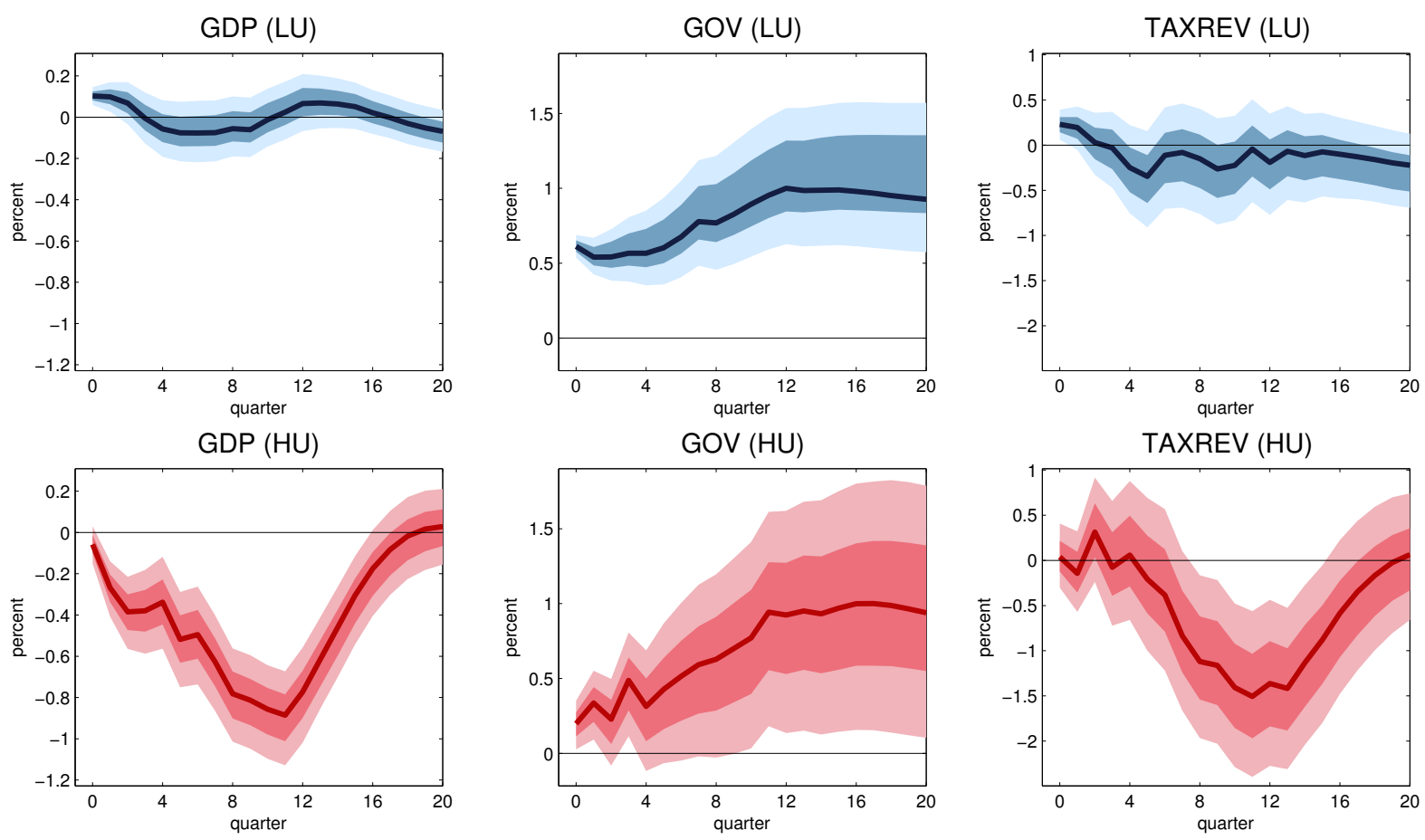

The top panel (in blue) shows responses to a government spending shock during times of low uncertainty. The bottom panel (in red) shows responses during times of high uncertainty. Government spending shocks are identified using Ramey (201la) defence spending forecast errors. The $68 \%$ and $95 \%$ confidence bands are computed using a non-parametric bootstrap. 
Figure 22: Responses during periods of $\mathrm{R}$ and $\mathrm{B}$ (alternative narrative identification)
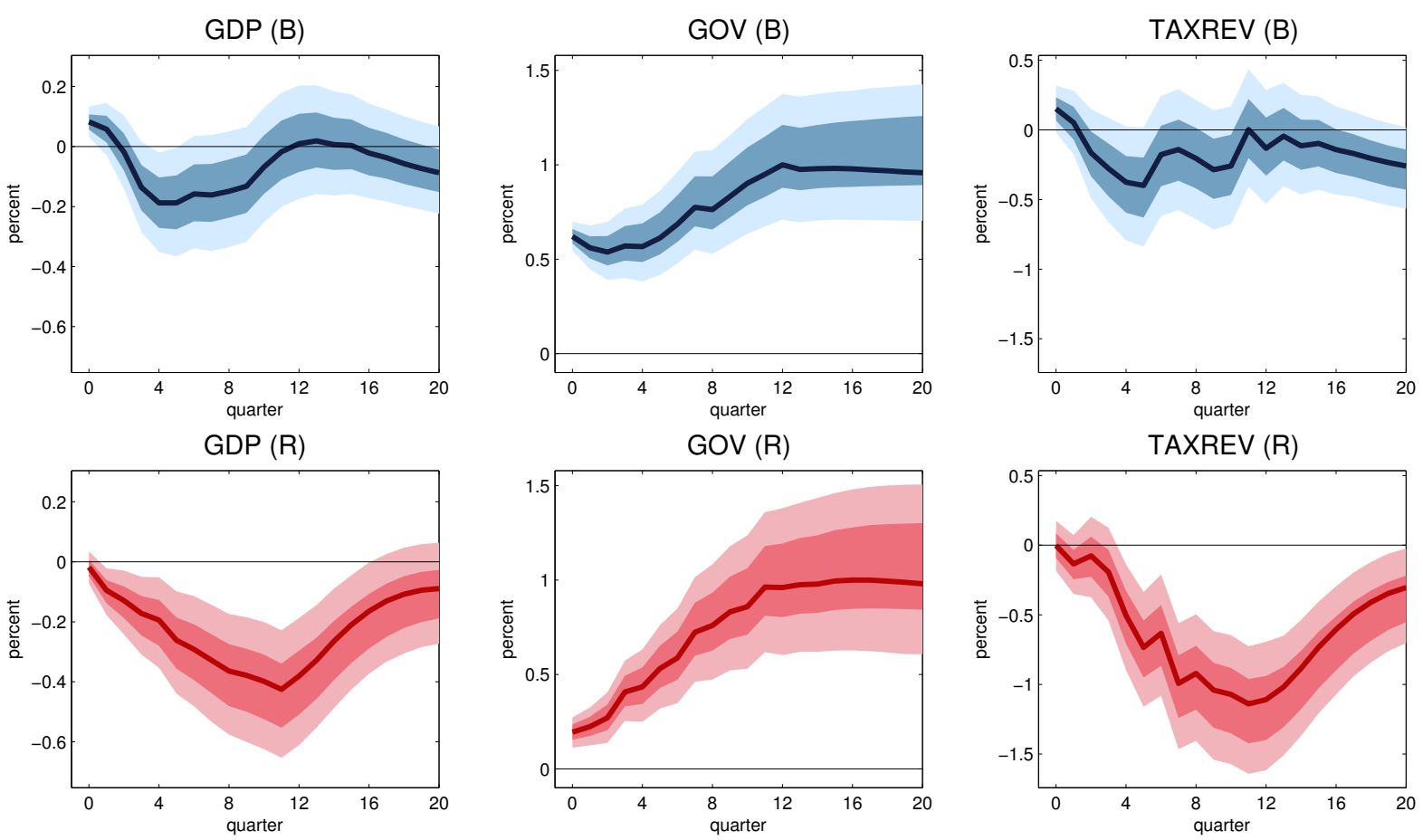

The top panel (in blue) shows responses to a government spending shock during times of boom. The bottom panel (in red) shows responses during times of recession. Government spending shocks are identified using Ramey (201la) defence spending forecast errors. The $68 \%$ and $95 \%$ confidence bands are computed using a non-parametric bootstrap. 


\section{Appendix}

\section{A. Data}

The following data are obtained from the BEA's NIPA tables (last revision on 20 December 2013)

- Output is Gross Domestic Product from Table 1.1.5 (line 1).

- Government Spending is Federal Government Consumption Expenditures and Gross Investment from Table 3.9.5 (line 9).

- Total Tax Revenues are Federal Current Tax Receipts from Table 3.2 (line 2) plus Contributions for Government Social Insurance from Table 3.2 (line 11) minus Taxes on Corporate Income taxes from Federal Reserve Banks from Table 3.2 (line 8).

- Consumption is Personal Consumption Expenditures from Table 1.1.5 (line 2).

All these variables are expressed in real terms, deflated by the GDP deflator from Table 1.1.9 (line 1), and in per capita terms (divided by the civilian population aged 16 or more from Francis and Ramey (200.9)).

Data from other sources:

- Consumer Confidence Index. Source: Conference Board (obtained via Thomson Reuters Datastream).

- Index of Consumer Sentiment. Source: Survey of Consumers, Thomson Reuters/University of Michigan.

- Business Confidence Indicator (industrial confidence in the manufacturing sector). Source: OECD (obtained via Thomson Reuters Datastream).

- Consumer Price Index. Source: BLS.

- Expected Inflation. Median expected price change during the next 12 months. Source: Survey of Consumers, Thomson Reuters/University of Michigan.

- Interest Rates. 3-Month Treasury Bill (Secondary Market Rate). Source: Board of Governors of the Federal Reserve System. 


\section{B. Robustness: Trend Specifications}

In Section $\mathbf{2}$, both equations $\mathrm{W}$ and $\mathbf{5}$ incorporate linear and quadratic trends, with the vector of variables $\boldsymbol{x}_{t}$ being in levels. In this subsection we reestimate these models, allowing for a stochastic trend by including the vector of variables in first differences (and omitting the deterministic trends).

Figure [A] compares the responses to government spending shocks identified with exclusion restrictions, in specifications with stochastic trends (solid lines) and with deterministic trends (dashed lines), during periods of $\mathrm{HU}$ and LU. In the latter case $(\mathrm{LU})$, the only noticeable difference is the permanent effect of the shock on government spending when allowing for stochastic trends. During times of HU, output shows a very similar pattern in both specifications during the first two years. After that, the effect of the shock starts to disappear in the benchmark specification (dashed lines) while the effect is permanent in the stochastic trends specification.

Similar results are obtained when we consider the different effects in times of B and $\mathrm{R}$ (Figure $\mathbf{A 4}$ ). Interestingly, output remains positive and significant during times of $\mathrm{B}$ for the entire horizon, as opposed to what happens in the benchmark specification (where the effect of the shock lasts for about a year). When allowing for stochastic trends, the shock has permanent effects on government spending during both $\mathrm{R}$ and $\mathrm{B}$ times. The responses of output during times of $\mathrm{R}$ are very similar in both trend specifications.

The same conclusions are reached when we repeat the analysis for the case of a government spending shock identified using narrative methods (equation 5). The responses during $\mathrm{HU}$ and LU (Figure $\mathbf{A 3}$ ) and during R and B (Figure A2) are fairly similar regardless of the assumption of deterministic or stochastic trends. During both $\mathrm{R}$ and $\mathrm{HU}$, the response of output shows permanent effects when stochastic trends are considered, while the effects of the shock are temporary in the benchmark specification. 
Figure A1: Responses during HU and LU (SVAR identification, specification in first differences)
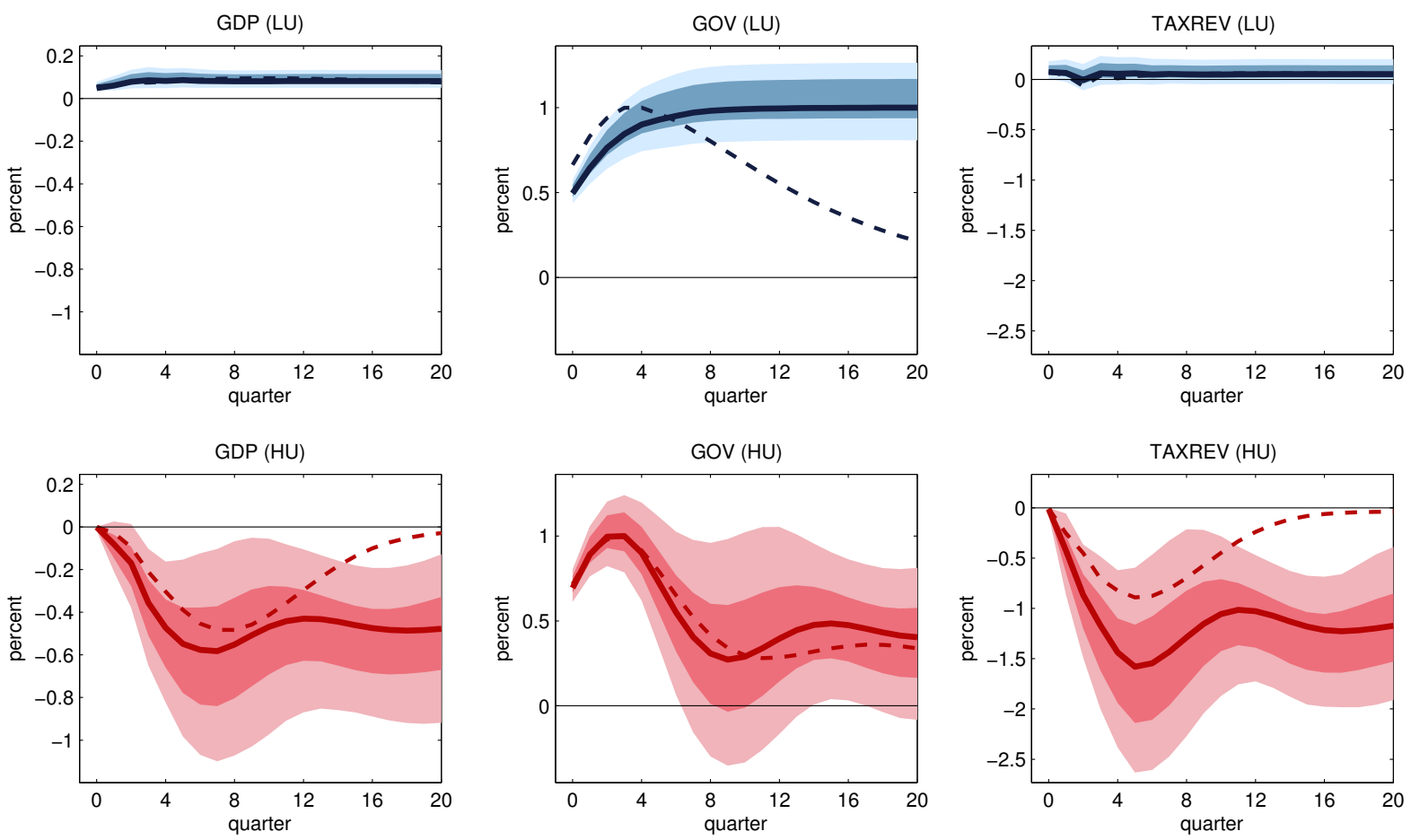

The top panel (in blue) shows responses to a government spending shock (identified using exclusion restrictions) during times of low uncertainty. The bottom panel (in red) shows responses during times of high uncertainty. The solid line plots the point estimates for the alternative specification using first differences. The dashed line plots the point estimates for the benchmark definition used in Section $\square$ with variables in levels. The $68 \%$ and $95 \%$ confidence bands are computed using a non-parametric bootstrap. 
Figure A2: Responses during R and B (SVAR identification, specification in first differences)
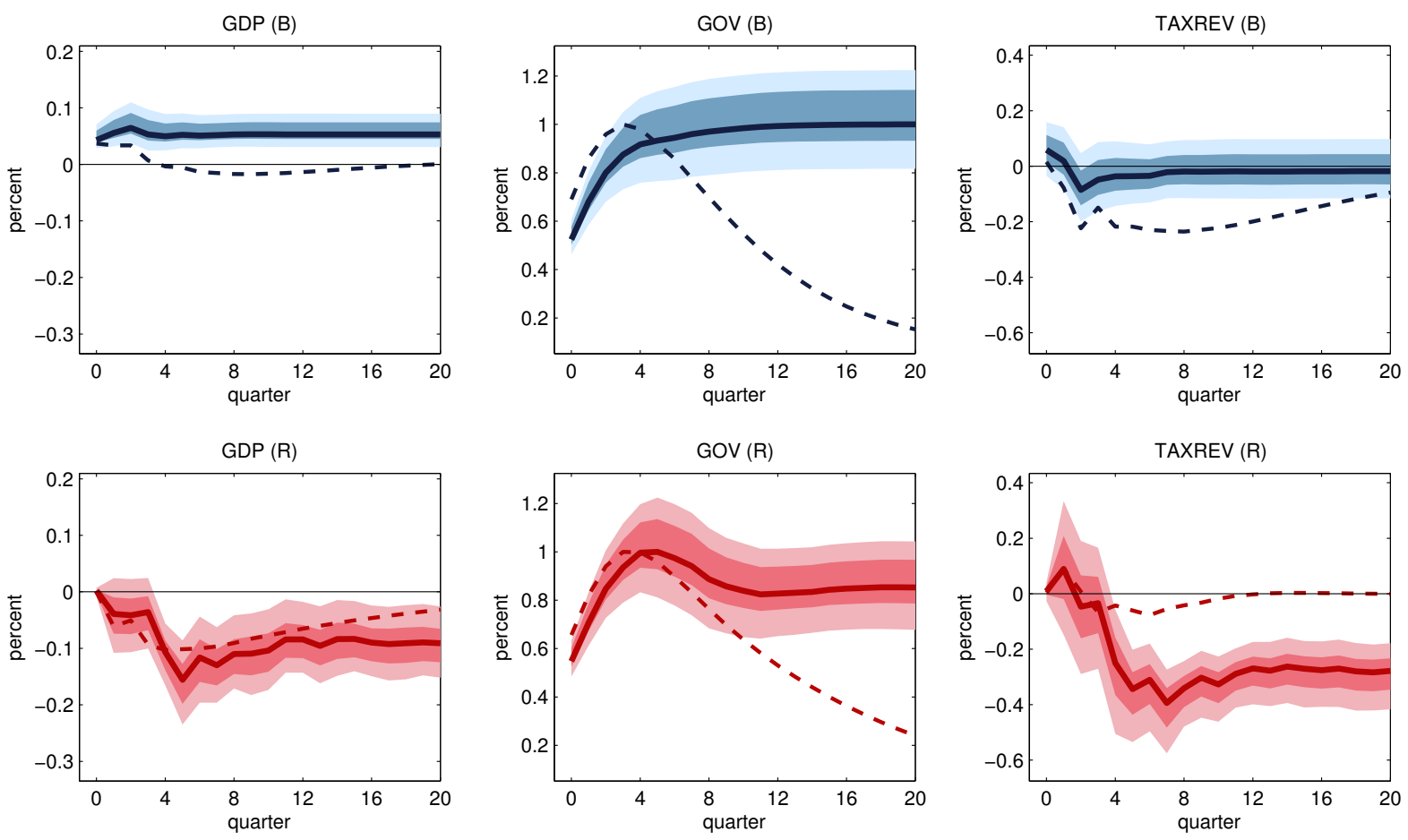

The top panel (in blue) shows responses to a government spending shock (identified using exclusion restrictions) during times of boom. The bottom panel (in red) shows responses during times of recession. The solid line plots the point estimates for the alternative specification using first differences. The dashed line plots the point estimates for the benchmark definition used in Section $\square$ with variables in levels. The $68 \%$ and $95 \%$ confidence bands are computed using a non-parametric bootstrap. 
Figure A3: Responses during HU and LU (narrative identification, specification in first differences)
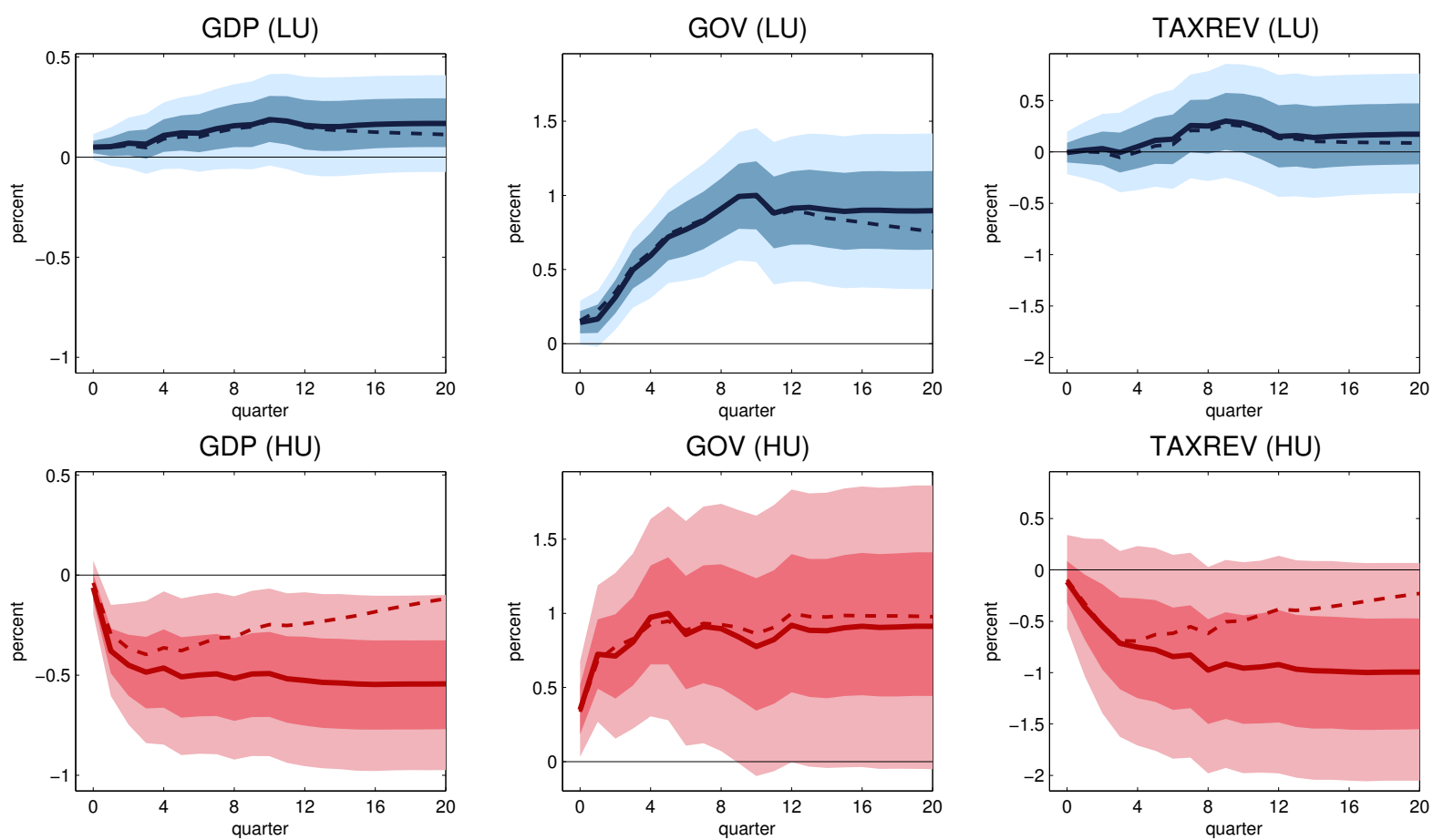

The top panel (in blue) shows responses to a government spending shock (identified from narrative accounts of defence spending) during times of low uncertainty. The bottom panel (in red) shows responses during times of high uncertainty. The solid line plots the point estimates for the alternative specification using first differences. The dashed line plots the point estimates for the benchmark definition used in Section $\square$ with variables in levels. The $68 \%$ and $95 \%$ confidence bands are computed using a non-parametric bootstrap. 
Figure A4: Responses during R and B (narrative identification, specification in first differences)
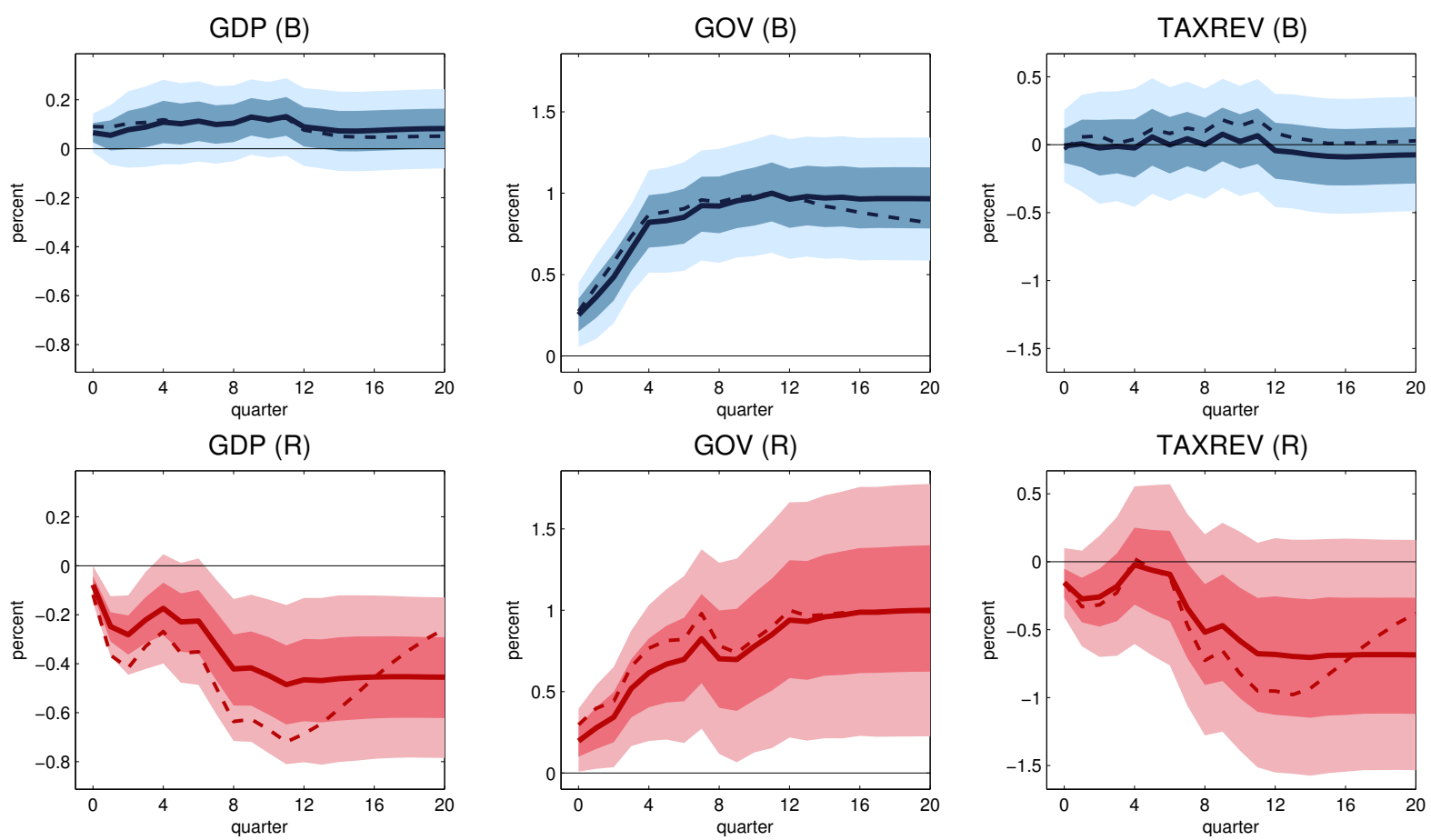

The top panel (in blue) shows responses to a government spending shock (identified from narrative accounts of defence spending) during times of boom. The bottom panel (in red) shows responses during times of recession. The solid line plots the point estimates for the alternative specification using first differences. The dashed line plots the point estimates for the benchmark definition used in Section $\square$ with variables in levels. The $68 \%$ and $95 \%$ confidence bands are computed using a non-parametric bootstrap. 